Illinois State University

ISU ReD: Research and eData

Theses and Dissertations

8-1978

\title{
Effectiveness of Professionals vs. Paraprofessionals in the Group Management of Test Anxiety
}

Matthew P. Bars

Illinois State University

Follow this and additional works at: https://ir.library.illinoisstate.edu/etd

Part of the Clinical Psychology Commons

\section{Recommended Citation}

Bars, Matthew P., "Effectiveness of Professionals vs. Paraprofessionals in the Group Management of Test Anxiety" (1978). Theses and Dissertations. 645.

https://ir.library.illinoisstate.edu/etd/645

This Thesis is brought to you for free and open access by ISU ReD: Research and eData. It has been accepted for inclusion in Theses and Dissertations by an authorized administrator of ISU ReD: Research and eData. For more information, please contact ISUReD@ilstu.edu. 


\section{EFFECTIVENESS OF PROFESSIONALS VS. PARAPROFESSIONALS IN THE GROUP MANAGEMENT OF TEST ANXIETY

$$
\text { Matthew P. Bars }
$$

74 Pages

August, 1978

This research investigated the effectiveness of professional and paraprofessional therapists in the group management of students exhibiting test anxiety. The two therapist groups were found to be similar in effectiveness. 


\section{EFFECTIVENESS OF PROFESSIONALS VS. PARAPROFESSIONALS}

IN THE GROUP MANAGEMENT OF TEST ANXIETY

Matthew P. Bars

74 Pages

August, 1978

This research was concerned with the relative effectiveness of professional and paraprofessional therapists in group management of college students exhibiting test anxiety. It was predicted that both the professional and paraprofessional therapists' groups would exhibit significant pre-post decreases in debilitating test anxiety. It was also predicted that there would be no significant pre-post differences between the professional and paraprofessional therapists' groups. Subjects were 26 participants in five Illinois State University Student Counseling Center Test Anxiety Workshops. Subjects completed a modified State-Trait Anxiety Inventory and Achievement Anxiety Test at the beginning and end of the test anxiety workshops.

The hypothesis that both the professional and paraprofessional therapists' groups would exhibit significant pre-post decreases in debilitating test anxiety was tested using related samples $\underline{t}$-tests on the STAI-S and DAAT data. Results supported the hypothesis.

The hypothesis that there would be no significant pre-post differences between the professional and paraprofessional therapists' groups was tested using analyses of covariance with the pre-STAI-S, pre-DAAT, and pre-FAAT scores as the covariates and the post-STAI-S, post-DAAT, and post-FAAT scores as the criteria. Results supported 
the hypothesis.

It was concluded that paraprofessional therapists compare favorably to professional therapists in the group management of college students exhibiting test anxiety. 


\title{
EFFECTIVENESS OF PROFESSIONALS VS. PARAPROFESSIONALS IN THE GROUP MANAGEMENT OF TEST ANXIETY
}

\author{
MATTHEW P. BARS
}

A Thesis Submitted in Partial

Fulfillment of the Requirements

for the Degree of

MASTER OF SCIENCE

ILLINOIS STATE UNIVERSITY

1978 


\section{ACKNOWLEDGMENTS}

The author wishes to thank Dr. James Johnson, Chairman of his Advisory Committee, and Drs. Robert Berger and James Clack, members of his Advisory Committee, for the assistance, encouragement, and guidance they provided during the writing of this thesis.

M. P. B. 
ACKNOWLEDGMENTS. ..................... i i

TABLE OF CONTENTS...................... i

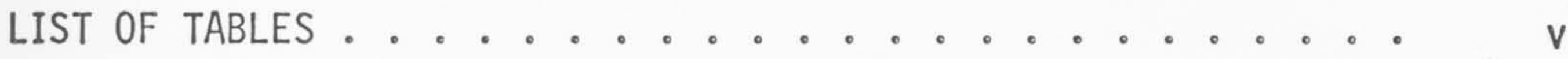

LIST OF FIGURES. ............................. vi CHAPTER

I. INTRODUCTION.................... 1

The Paraprofessional Defined. . . . . . . 2

The Historical Development of the Paraprofessional Concept. ........ 4

The Clinical Functions of Paraprofessional

Therapists. . . . . . . . . 9

Evidence Concerning the Clinical Effectiveness of Paraprofessional Therapists .... 10

The College Paraprofessional. . . . . . . 27

The Management of Test Anxiety. . . . . . 31

Present Study .............. 35

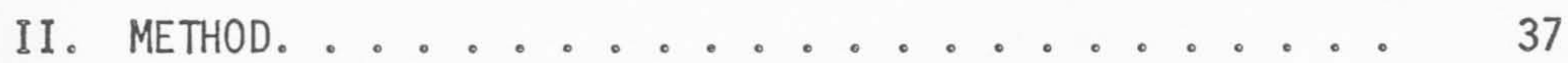

Subjects............... 37

Instruments ................. 37

Therapists. . . . . . . . 40

Procedure ................. 42

III. RESULTS ...................... 45

Overall Decreases in Debilitating Test Anxiety. . 45

Decreases in Debilitating Test Anxiety by

Therapist Group ........ 46

Individual Workshop Differences . . . . . . 49

Workshop Attrition Rates. . . . . . . 49

IV. DISCUSSION. ...................... 50

Overall Decreases in Debilitating Test Anxiety. . 50

Decreases in Debilitating Test Anxiety by

Therapist Group ......... 53

Workshop Attrition Rates. . . . . . . . . 54

Limitations of the Study and Future Research. . . 54 
REFERENCES. . . . . . . . . . . . . . . 57

APPENDIX A: STAI-S Test Anxiety Questionnaire........ 68

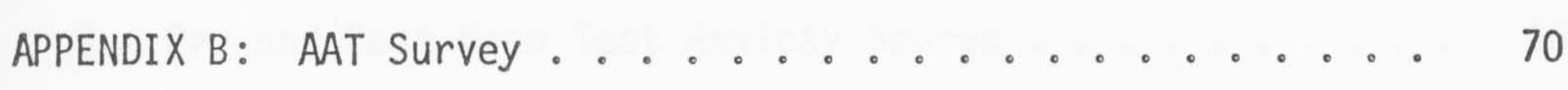

APPENDIX C: Subject Test Anxiety Scores.......... 73 


\section{LIST OF TABLES}

Table Page

1. Pre and Post Mean Test Anxiety Scores ....... 46

2. Mean and Adjusted Post-Mean Test

Anxiety Scores.............. 47

3. Analyses of Covariance for Decreases in

Debilitating Test Anxiety Between

Professional and Paraprofessional

Therapists' Groups. ........... 47

4. Analysis of Covariance for Increases in

Facilitating Test Anxiety Between

Professional and Paraprofessional

Therapists' Groups. . . . . . . . . 4 48

5. Test Anxiety Pre-Post Mean Differences

by Therapist Experience ........... 48 


\section{LIST OF FIGURES}

Figure

Page

1. A year-by-year tabulation of the number of books and articles on nonprofessional personnel which have appeared in the professional literature during the past decade. 


\section{CHAPTER I}

\section{INTRODUCTION}

The paraprofessional as a new type of mental health worker was originally encountered over 40 years ago (Felton, Wallach, \& Gallo, 1974). While the possibility of paraprofessional utilization has been discussed periodically since World War II (Arnhoff, Jenkins, \& Speisman, 1969), it was not until the late 1950's that the notion received serious consideration. Since then, the role of the paraprofessional worker has expanded to include a wide range of clinical roles and functions. Although paraprofessional utilization in the field of mental health has increased dramatically, its full potential has not yet been realized (B10om, 1977).

The present study attempts to determine whether or not paraprofessional utilization can be extended to include the therapeutic management of $\mathrm{clients} \mathrm{experiencing} \mathrm{test} \mathrm{anxiety} \mathrm{in} \mathrm{the} \mathrm{academic} \mathrm{com-}$ munity. Topics covered in this chapter will include a definition and discussion of the nature of the paraprofessional worker. Discussion will also include the historical development of the paraprofessional concept, the clinical functions paraprofessional therapists perform, evidence concerning the clinical effectiveness of paraprofessional therapists, the college paraprofessional, and the therapeutic management of test anxiety. 


\section{The Paraprofessional Defined}

A plethora of paraprofessional programs has been developed since the late 1950's. Many of these share the model proposed by Jesse Gordon (1965). Although it may vary within wide parameters, and be referred to by a variety of different names, the model basically consists of less than complete professional education in which training is directed at relatively specific functions.

Paraprofessionals have characteristically been defined according to the amount of formal training received. Paraprofessionals are considered to be individuals without training in established, formalized, professional-training programs who are usually involved in supervised contacts with persons seeking help, with such contacts either implicitly or explicitly presumed to be of a therapeutic influence. They are involved in therapeutic contacts formerly performed by professional workers.

Paraprofessional populations have differed in terms of age, socioeconomic status, education and training, previous life experiences, and position in the social status hierarchy. Paraprofessional personnel have included housewives, ex-drug addicts, welfare organizers, teenagers, clients and college students.

Gartner (1971) has identified three basic types of mental health paraprofessionals. The first is the "hospital-based worker." This individual is typically a psychiatric aide who is employed in a hospital setting providing therapeutic support. For the most part, they do not possess a college education nor are they indigenous to the community in which they work. Secondly, the "new middle-class 
paraprofessional" is usually, but not exclusively, female and possesses a college education. These individuals receive special training in mental health skills and are actively involved in therapeutic tasks. The third type has been referred to as the "indigenous paraprofessional." As such, they are residents of the community in which they work. Typically, the indigenous paraprofessional is employed in a community mental health center and does not hold a college degree. The indigenous paraprofessional, also, is engaged in significant therapeutic work.

These mental health workers have alternatively been referred to as "nonprofessionals," "peer counselors," "subprofessionals," "new professionals," "lay therapists," or "auxiliary personnel," "technical personnel," as well as "paraprofessionals." ${ }^{\dagger}$ The terms "student counselor" (Zunker \& Brown, 1966), "mental health counselor" (Rioch, Elkes, Flint, Usdansky, Newman, \& Silber, 1963), "aide-therapist" (Truax, 1965), and "human service worker" (Felton, Wallach, \& Gallo, 1974) have also been used. Lamb and LaFave (1975) have indicated that the majority (84\%) of paraprofessionals at University Counseling Centers were identified by specific titles, with "peer counselor" (21\%) and "paraprofessional" (20\%) being applied most frequently. Conversely, Gartner (1971) has defined mental health professionals as those individuals holding postbaccalaurate professional

Then job titles are included within quotation marks, the reference is specific to the job title, the term paraprofessional, etc. is meant to be taken as a generic term meaning a nontraditionally trained mental health worker. 
degrees and excludes those engaged only in maintenance and housekeeping activities. Similarly, Steele (1974) defined professionals as those individuals who have completed academic or applied training in a helping field. This definition is quite broad and includes social workers, pastoral counselors, rehabilitation counselors, psychiatrists, psychologists, physical therapists, activity-therapists, art and play therapists, music therapists, and other comparably trained personnel.

\section{The Historical $\frac{\text { Development }}{\text { the }}$ of}

Gartner and Riessman (1974) have identified five major factors instrumental in the development of paraprofessional personnel in the mental health field. These include: (1) the realization that certain target populations, particularly the poor and minorities, received inadequate treatment delivery by professional therapists; (2) the recognition that the poor were locked out of achieving professional status by traditional credentialing paths, which require long periods of education prior to job placement; (3) paraprofessionals becoming more acceptable to the professional community, who recognize them as a bridge to the poor; (4) the realization that there was a need for jobs and that paraprofessionals with an understanding of the community and a minimal amount of training could generate new jobs; and (5) the realization that paraprofessionals, particularly in terms of service delivery, could provide much needed mental heal th manpower.

Similarly, it has been echoed by others that the welldocumented deficiency in the delivery of mental health services precipitated, to a significant degree, the utilization of 
paraprofessionals in the past 15 years (Arnhoff, Jenkins, \& Speisman, 1969; Kalafat \& Boroto, 1977). Mental health professionals have consistently been found unable to supply the manpower demanded for services (Albee, 1968; Cowne, 1969). Indeed it appears that the need and demand for mental heaith resources can never be adequately handled exclusively by professional workers (Durlak, 1973).

The professional response to the need for new manpower sources is indicated in the recommendations of the Joint Commission of Mental I11ness and Health (1961) to develop new occupations and manpower sources. Alternatives to traditional psychotherapeutic treatment and training have also been proposed in the reports of the 1958 Miami Conference on Graduate Education in Psychology (Roe, Gustad, Moore, Ross, \& Skodak, 1959), the 1965 Chicago Conference on the Professional Preparation of Clinical Psychologists (Hoch, Ross, \& Winder, 1966), and the 1973 National Conference on Levels and Patterns of Professional Training in Psychology (Korman, 1976).

The term "nonprofessional revolution" has been used to describe this rapidly growing, highly influential mental health development and demonstrates how far the concept has progressed (Hobbs, 1964; Cowen, 1973; Durlak, 1973). A sampling of the literature on the utilization of paraprofessionals indicates that they are becoming an integral part of the mental health system. For example, Scheur (1969) estimated that there were over 500,000 nonprofessionals employed in human service fields. Similarly, Gartner, Nixon, and Riessman (1973) have stated that the fact that 500,000 to $1,000,000$ people have acquired jobs as paraprofessionals is no minor accomplishment. The 
data indicating that their involvement has led to improved human services has also been said to be significant.

One measure of the scope of this movement is found in the massive number of recent volumes concerning paraprofessional utilization. Durlak (1971, p. 11) has presented a year-by-year tabulation of the books and articles on the use of nonprofessional personnel that have appeared in psychological literature for the years 1960 to 1969. The successful use of paraprofessionals in a wide range of counseling roles has been reported with ever increasing frequency as represented in Figure 1.

One explanation given for the incomplete utilization of paraprofessionals in the mental health field is provided separately by Baker (1973), Cowen (1973), and Maierle (1973). They have all stated that one major obstacle to paraprofessional utilization is resistance on the part of professional mental health workers. However, much of this professional resistance seems to be empirically unsupported considering the available literature on paraprofessional performance. Despite the many problems that have been assumed to involve paraprofessional personnel, few if any, have materialized (Durlak, 1973). Kalafat and Boroto (1977) and Crisler (1973) have suggested that the lack of definition of the roles and functions of the paraprofessional could explain their incomplete utilization in human service programs. They add that it is time for specification in terms of paraprofessional selection, training, roles, and functions. This sharpening of focus, Crisler (1973) continues, would aid in the evaluation of paraprofessional personnel and in addition, would 


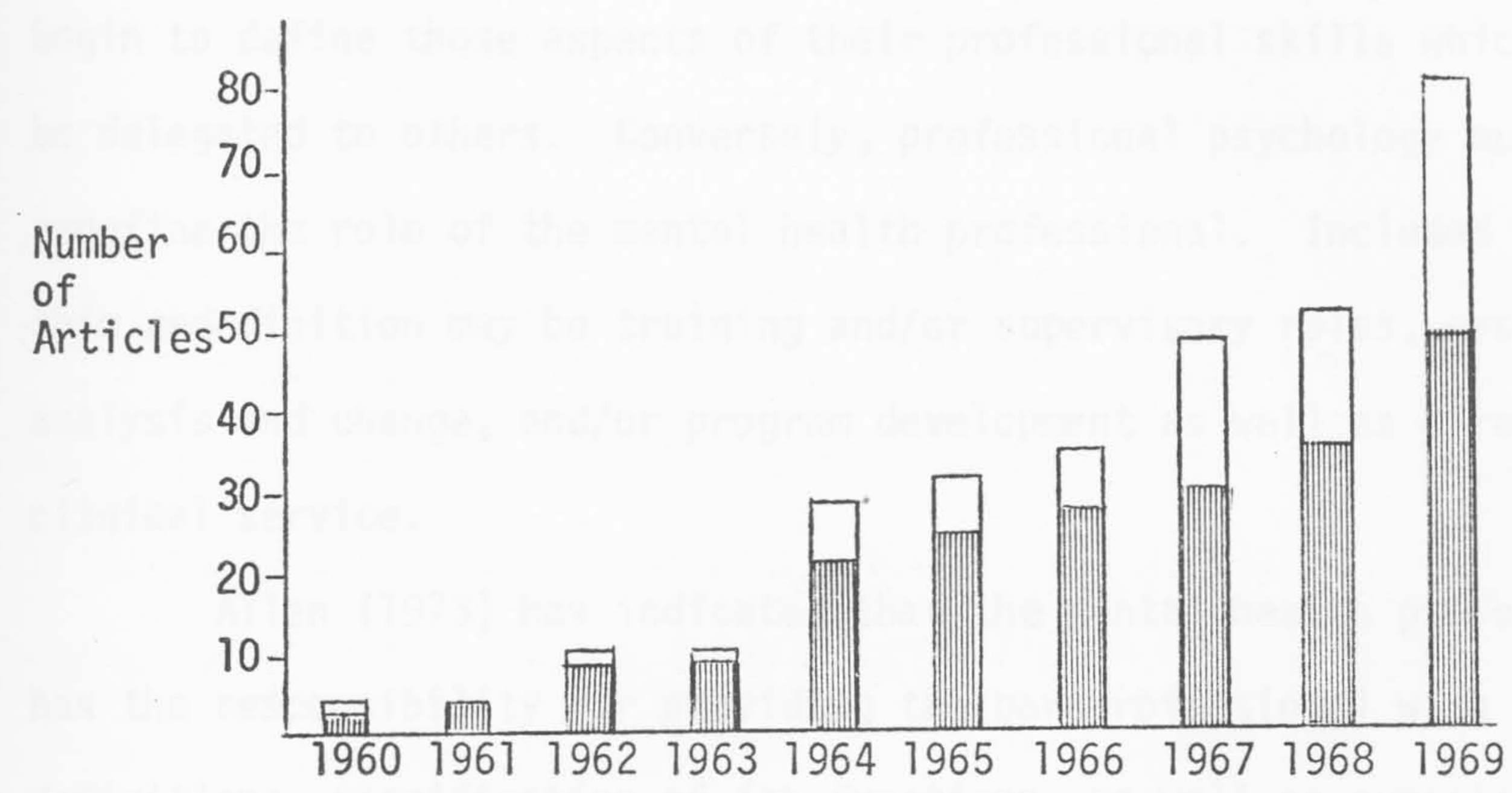

Figure 1. A year-by-year tabulation of the number of books and articles on nonprofessional personnel which have appeared in the professional literature during the past decade. The height of each bar graph represents the total number of general references on the selection, training, and use of nonprofessionals and the shaded portion of each graph indicates the number of studies reporting some empirical data with regard to these issues.

Source: Durlak, J. A. The use of nonprofessionals as therapeutic agents: Research, issues and implications. (Doctoral dissertation, Vanderbilt University, 1973). Dissertation Abstracts International, 1971, 32, 2999B3000B. (University Microfilms No. 71-29, 298) 
prohibit evaluation against inappropriate, professional criteria (Bartels \& Tyler, 1975; Kalafat \& Boroto, 1977).

Similarly, Weinberger (1972) has suggested that professionals begin to define those aspects of their professional skills which can be delegated to others. Conversely, professional psychology must redefine the role of the mental health professional. Included in this redefinition may be training and/or supervisory roles, systems analysis and change, and/or program development as well as direct clinical service.

Allen (1973) has indicated that the mental health professional has the responsibility for providing the paraprofessional with role definitions, specification of job functions, as well as expectations and limitations. He adds that the lack of clear role definition and job performance criteria has nearly wrecked some programs because of the paraprofessionals' uncertainty about what was expected of them. He adds that one professional responsibility is to help paraprofessionals assume greater responsibilities.

Consequently, Kalafat and Boroto (1977) have proposed the establishment of clear roles for paraprofessionals as a first step toward the solution of problems with paraprofessional utilization. Along this line it has been stated that some paraprofessional counselors are better trained than professional workers in performing specific intervention services. Because paraprofessional helpers often work in more narrowly defined areas and often with particular target groups, for example, welfare mothers, indigenous people, the poor, and different student cultures, it is only logical that their 
competence should be recognized.

Such specificity is needed due to the diversity of paraprofessional involvement in the mental health field. Paraprofessional development has varied greatly in terms of factors such as helper and client populations, settings, roles and functions.

\section{The Clinical Functions of Paraprofessional Therapists}

Extensive literature has been presented concerning the effectiveness of paraprofessional counselors in community and anti-poverty programs (Gartner, 1969; Gordon, 1965; Reiff \& Riessman, 1965); in mental hospitals and outpatients clinics (Carkhuff, 1969; Carkhuff \& Truax, 1965; Ellsworth, 1968; Magoon \& Golann, 1966), and on school and college campuses (Brown, 1972; Cowen, Zax, \& Laird, 1966; Persons, Clark, Persons, Kadish, \& Patterson, 1973). Paraprofessionals have been found providing services in juvenile detention centers and courts, nursery schools and day care centers, and many other clinical settings.

Sobey (1970) systematically examined the utilization of paraprofessionals in 185 programs sponsored by the National Institute of Mental Health. In many programs paraprofessionals were routinely performing such therapeutic functions as individual counseling, activity group therapy, milieu therapy, special skill training, community adjustment, case finding orientation to services, screening and caretaking. Paraprofessionals have been found providing effective social skill training to psychiatric inpatients (Crowe, 1975); applying behavior modification techniques with handicapped children (Davison, 1965; Hawkins, Peterson, Schweid, \& Bijou, 1966); functioning 
as a chemotherapist, prescribing medication without medical supervision (Platman, Dorgan, \& Gerhard, 1974-1975); as well as a plethora of other innovative treatments (Durlak, 1971).

Thusly, the most fruitful line of investigation in this area has been directed not merely at answering "are paraprofessionals effective therapeutic agents" but is more specifically focused on the question of "what form of intervention on the part of what kind of helping persons will be of greatest benefit to what kind of clients in what sets of circumstances?" (Durlak, 1971, p. 348) Such specificity is the focus of the present study. This study is an attempt to empirically investigate professional and paraprofessional effectiveness in the group management of test anxiety at a university counseling center.

\section{Evidence Concerning the Clinical Effectiveness of Paraprofessional Therapists}

Durlak (1971) has described both direct and indirect evidence to support the claim that paraprofessional personnel may be particularly effective in their interpersonal relationships with troubled individuals. Two of the sources of indirect evidence cited include: (1) evidence supporting the notion that it is the therapist with certain personal qualities and certain ways of responding that produces positive results; and (2) the observation that professional training programs have failed to provide evidence of their effectiveness.

There is a growing body of literature which suggests that the therapeutic outcome may be more closely related to the personal characteristics of therapists rather than to their technical background and training. These variables identified as critical to successful 
therapy are alternately referred to as therapist-offered conditions, therapeutic conditions, levels of interpersonal functioning, or facilitative conditions (Durlak, 1971). The literature is much too extensive for a complete review, only an overview will be provided.

In this vein, Carl Rogers (1957) has stated that "intellectual training and the acquiring of information has many valuable results-but becoming a therapist is not one of those results" (p. 101). Rogers (1951, 1957) has emphasized the importance of relationship variables in the therapeutic encounter which he saw as necessary and sufficient for client improvement. These variables have been identified as congruency unconditional regard and empathic understanding.

Truax, Carkhuff and others following the pioneering work of Rogers have found a number of variables which can be correlated with client improvement. The variables are: empathy, non-possessive warmth, genuineness, concreteness, self-disclosure, confrontation and immediacy (Cannon \& Carkhuff, 1969). Immediacy, a less common concept than others, refers to the therapist understanding and interpreting events in the therapeutic relationship, as they occur (Carkhuff, 1969). Truax (1965) attempted to identify those characteristics which make for more effective counseling and for the use of lay counselors. He isolated three factors as crucial to the therapist's effect on his clients: communicating a high level of accurate empathy, nonpossessive warmth, and genuineness to the client.

Paraprofessionals have been found to possess certain characteristics which might render these individuals the mode of choice in the delivery of some clinical services (Stevenson \& Viney, 1973). 
Some of these identified qualities on which they differ from professional therapists are their enthusiasm and positive expectations, their lack of professional roles and techniques that can produce distance between the helper and the client, their openness to innovative strategies, their social position, knowledge of the community, and their lifestyle which assists them in gaining entry and establishing rapport with a variety of clients (Reiff \& Riessman, 1965; Sobey, 1970).

Cowen (1973) has stated that the paraprofessional brings such factors as enthusiasm, vibrancy, dedication, and naively positive expectancies to the therapeutic encounter. They are better able to gain entry and establish rapport because there is less social distance between themselves and their clients. They are less encumbered by rigid and sometimes spurious rules, permitting freer, unfettered exploration of diverse therapeutic avenues and can often interact more naturally with their clients than professional therapists.

Similarly, Rioch (1966) has stated that one factor contributing to paraprofessional effectiveness may stem from the clients' perception of the paraprofessional as a person close to themselves in the social hierarchy. Furthermore, Rioch has suggested that the paraprofessional possesses more flexibility in the therapeutic encounter and is able to relate to the client in significant new ways (Holzberg, 1963).

Opplinger (1971) stated that the paraprofessional can provide the client with a more appropriate model of social interaction than the professional. Carkhuff (1969) and Reiff and Reissman (1965) both 
have stated that the paraprofessional empathizes more with the life style of the client and is able to become sufficiently involved to actively participate in the client's life.

Carkhuff (1968) has described the characteristics of the paraprofessional therapist. These include: (a) the increased ability to enter the milieu of the distressed, (b) the ability to establish peerlike relationships with the needy; (c) the ability to take an active part in the clients' total life situation; (d) the ability to teach the client more successful actions, from within the clients' frame of reference; and (e) the ability to provide clients, with a more effective transition, to more effective levels of functioning within the social system. These characteristics apply to the more traditional type of indigenous mental health worker as well as the college paraprofessional.

A number of researchers have indicated the clinical usefulness of commonality of background between therapist and client (Carkhuff \& Truax, 1965; Carson, 1967; Deane, 1960; Deane \& Ansbacher, 1962; Strupp \& Bergin, 1969). Continuing with this theme, Reiff and Riessman (1965, p. 7) state that the therapeutic ability of the indigenous paraprofessional is "rooted in their background. It is not based on things they have been taught, but on what they are." Paraprofessionals can establish special relations with their clients-the paraprofessional belongs, he is a significant other, he is a member. His life style is similar to that of the client. Similarly, Steisel (1972) has stated that the rationale for using indigenous paraprofessionals is that they consider themselves 
and are considered members of the environment. They are able to identify with community residents and exhibit greater sensitivity to their needs. In addition, the paraprofessional is more attuned to community mores, more empathetic to problems, and more likely to be responded to in contrast to the middle class professional.

Wasserman, Messersmith, and Ferree (1975) have stated that paraprofessional helpers, particularly those indigenous to the ethnic, socioeconomic class, or specific problem of the prospective clients, often do have greater understanding, form closer relationships, and use appropriate vocabulary more effectively than professionals. Gruver (1971) has stated that one reason the focus upon college students as paraprofessionals is relevant is because they appear to have qualities and characteristics which may suit them to work with troubled individuals.

Gruver continues that if, as some authors (Rogers, 1957; Truax \& Wargo, 1966) suggest, accurate empathy is the single most important therapist characteristic in determining the outcome of therapy, then college students instantly and automatically have an advantage over their professional counterparts via their social status. Furthermore, if feeling closer to the therapist in terms of social status and commonality of background does facilitate "instantly felt empathy," then college students should be even more effective working with other college students and certain other similar populations.

In summary, Gruver adds it appears that college students may have an advantage in working with some populations by virtue of their not having prior training or professional status. Poser (1966) has 
concluded that, in fact, the college students' energy, naive enthusiasm and lack of professional stance may contribute to these individuals' superior clinical performance.

Much evidence has accumulated indicating that clients do place a great amount of emphasis upon the personal characteristics of their therapists. For example, Strupp, Fox, and Lessler (1969) found, in a questionnaire study, that clients' attitudinal responses suggested that a number of therapist characteristics were related to the clients' acceptance and liking, for their therapist.

The clients' acceptance and liking of the therapist was also found to be related to client improvement in psychotherapy.

Many authors have stated that the selection of graduate students on the basis of intellectual indices does not produce more successful therapists as measured by client improvement (Bergin, 1966; Carkhuff, 1966; Rioch, 1966; Rogers, 1957). Bergin and his associates have found ratings of empathy, to be negligibly, if not negatively, correlated with intellectual indices. Bergin and Solomon (1968) originally reported correlations between ratings of empathy and graduate trainee's grade point average and practicum grades of -.17 and -.16 , respectively. In a replication study, Bergin and Jaspers (1969) found the respective correlations to be .01 and .07. Carkhuff (1969) has explained that the comparatively greater effectiveness of paraprofessional therapists that is often reported in the literature may have resulted from the selection of paraprofessionals who were more health-engendering individuals than the professional therapists. This is not surprising since the two selection 
processes differ significantly as Brown (1974) and others have pointed out. Paraprofessional programs carefully select individuals exhibiting psychological health while professional training programs emphasize selection based on intellective factors.

Similarly, Anker and Walsh (1961), Beck, Kantor, and Gelineau (1962), Rioch, Elkes, Flint, Usdansky, Newman, and Silber (1963), and Schofield (1964) have all indicated that professional training is not necessary for effective psychotherapy. Most of these authors have provided objective data confirming this statement. Poser (1966) has concluded that his findings support the contention that traditional professional education may not be warranted nor even necessary for therapeutic change. Powell (1975, p. 19) adds that as a profession "we are beginning to realize that a Ph.D. in psychology, an extensive background in research, and many publications are not the only requisites for being an effective therapist."

Furthermore, varying levels of counselor training have been found to be unrelated to clinical effectiveness. Engelkes and Roberts (1970) investigated the effectiveness of four levels of mental health worker education--post-master's degree, master's degree, bachelor's degree, and less than a bachelor's degree. It was found that higher levels of academic training of the rehabilitation counselors used in the study did not result in higher supervisor ratings for the overall effectiveness of the counselor. Higher levels of academic training did not result in higher client reports of satisfaction with their counselor. Truax and Lister (1970, p. 334), using three different therapist groups, concluded that their findings were "consistent with 
a growing body of research which indicates that the effectiveness of counseling and psychotherapy, as measured by constructive changes in client functioning, is largely independent of the counselor's level of training and theoretical orientation."

Although he didn't use a direct measure of client functioning, Truax (1965) found no significant differences between lay counselors, graduate student trainess, or experienced counselors in communicating accurate empathy or nonpossessive warmth. However, it was found that the experienced therapists demonstrated significantly higher performance in communicating genuineness to the client than did the other two therapist groups.

Thus far it has been demonstrated that (1) the personal characteristics of the therapist seem to be an important factor in effective therapy and that (2) traditional graduate training programs in psychology may not be producing graduates with demonstrably superior clinical skills in comparison to paraprofessional personnel.

Closely related to the indirect evidence concerning the effectiveness of professional training programs is the overwhelming majority of direct empirical studies which indicate a great amount of therapeutic success for paraprofessional personnel. Durlak (1971) in a systematic review of the literature found 13 studies that used various experimental procedures to directly compare the therapeutic effectiveness of nonprofessionals and professional personnel. However, only a sampling of these studies, most relevant to the present study, will be reviewed here. 
Poser's (1966) classic study evaluated the effectiveness of group therapy with chronic schizophrenic patients conducted by untrained paraprofessionals and experienced professional therapists. The untrained therapists consisted of 11 college coeds as well as two psychiatric inpatients. The professional therapists included seven psychiatrists, six psychiatric social workers and two occupational therapists. These therapists had from five to 17 years of professional experience and five were considered specialists in group psychotherapy.

Poser divided 343 male chronic schizophrenic patients into groups of 10 with each group matched as closely as possible with respect to patient age, severity of illness, length of hospitalization, and pre-therapy psychological test results (including fingertapping, visual reaction time, digit symbol, word association tasks, color-word conflict test and verbal fluency test). Groups were then randomly assigned to either a professional therapist, paraprofessional therapist, or to an untreated control condition. Each therapist met with his or her group for one hour each day, five days a week, for five months. All therapists were free to conduct their therapy sessions as they wished. Results were interpreted using the difference in pre-therapy and post-therapy scores on the six different psychological tests. Statistical analysis indicated that the patients seen by the paraprofessional therapists were slightly superior in the psychological test results to the patients seen by professional therapists. The untreated controls demonstrated the poorest performance. A three year follow up on the paraprofessionals' 
patients indicated that their test performance had not appreciably diminished from the original post scores.

Ellsworth (1968) in a well-controlled experiment demonstrated that paraprofessionals can contribute to improved treatment outcomes for hospitalized male schizophrenics. The program was designed to raise the quality and quantity of aide-patient interaction. Toward this end the aide's role in the hospital had to be altered, particularly as it related to participation in decision-making regarding their patients' progress (i.e., it was primarily up to the aides to decide on such matters as patient privileges, transfer to another ward, and the patients' securing a job either on or off hospital grounds). The study was conducted at the Veteran's Administration Hospital, Fort Meade, South Dakota. Patients of one building were used as experimental group ( $n=122)$ while the patients of two other buildings (employing traditional hospital procedures) served as controls. The experimental and control groups were carefully matched and divided into three subgroups based on length of hospitalization: 0-2 years (Group I), 2-5 years (Group II), and 5 years or more (Group III). Each of the 336 patients were evaluated over a 30 month period. Outcome measures were based on seven indices: level of behavioral adjustment, median days subsequently hospitalized, released versus not released, percent achieving twelve consecutive months in the community, good social adjustment, good work adjustment, and discharge status six years later.

Overall results on the seven treatment criteria clearly indicated that the aide program was significantly more effective than the 
other hospital programs. Ellsworth (1968) found that a higher percentage of patients from the experimental group were released to the community during the 30 -month demonstration period, and a lower percentage of them had to return to the hospital. The treatment differences were greatest, and statistically significant, on all seven criterion measures for the long term patients. The treatment differences were the least for the acute group. However, in this group the experimental program was significantly more effective on the criterion of patients remaining in the community for 12 consecutive months following hospital releases. Ellsworth (1968, p. 165) concluded that the project

- . has shown clearly that the role of a nonprofessionally trained person can be modified extensively in a psychiatric rehabilitation setting. When this modification takes the form of actively involving the nonprofessional in all phases of patient rehabilitation the treatment outcome for hospitalized male schizophrenics is highly significant.

Brown and his associates have completed a series of investigations into the effectiveness of paraprofessional counseling in academic environments. In a carefully controlled study utilizing several measures, Zunker and Brown (1966) compared the academic adjustment counseling provided by professional school counselors and college student counselors. The four professional counselors and the eight college paraprofessionals were trained under identical conditions, followed identical counseling activity sequences, and were provided equivalent counseling facilities. Three hundred and twenty freshmen from Southwest Texas State College served as subjects. One hundred sixty of the subjects, half males and half females, received academic 
counseling from same-sex professional counselors. A control sample of 80 men and 80 women were drawn from those freshmen counseled by student counselors. Students receiving professional counseling were carefully matched with students receiving paraprofessional counseling on the basis of age, sex, scholastic ability (ACT scores), high school quartile rank, and study orientation. The Effective Study Test, Counseling Evaluation Questionnaire, Study Skill Survey, Counseling Comprehension Test and grade point averages were used as outcome measures. Student counselors were found to be as effective as the professional counselors on all criteria of counseling effectiveness; in fact, student counselors achieved significantly better results than did the professional counselors on the majority of variables used to assess treatment outcome. In addition, student counselors received a greater degree of acceptance from their clients, and their clients made significantly greater use of the information received during counseling.

In a study with a paraprofessional population very similar to the present study, Wolff (1969) investigated the effectiveness of discussion groups led by four resident undergraduate dormitory advisors (DA's) and four advanced graduates in clinical psychology. The weekly discussions concerned college adjustment and interpersonal relations. Discussion groups were led by either the psychology graduate students or dormitory advisors. Two control groups were used also. Various interpersonal adjustment and behavioral indices, including a sociometric questionnaire, an activity form (number and type of extracurricular activities), and a time sample (percentage of 
time spent alone), were collected on the four groups of subjects. The results indicated that in comparison to both control groups the combined treatment groups were significantly more effective in producing positive change in the interpersonal activities and relations of its participants. A comparison of the two experimental groups indicated that the graduate student-led groups were superior in the percentage of client satisfaction ratings obtained by its members while the groups led by the dorm advisors were more effective in promoting social participation and companionship. Thus no clearcut superiority was indicated for either discussion group.

In 1960, the National Institute of Mental Health's Adult Psychiatry Branch funded Margaret J. Rioch's Mental Health Counselor program (Rioch et al., 1963). This early paraprofessional program was designed to provide mental health manpower, which could present low cost psychotherapeutic services. Eight women were selected from 80 applicants. All eight women completed four semesters of training which emphasized professional breadth, not technical specificity.

In one study stemming from the program, Magoon and Golann (1966) examined the therapeutic effectiveness of the eight mental health counselors. Supervisors familiar with the services provided by the paraprofessionals evaluated their competence in comparison to three different reference groups: (a) new therapists starting their first professional position, (b) social workers in their first postmaster's degree position, and (c) a reference group of the supervisor's own choosing. 
The results indicated that the mental health counselors were providing very effective counseling in comparison to the reference groups. In addition, all agency directors indicated they would hire other similarly trained paraprofessionals.

With treatment groups similar to the present study, Truax (1967) investigated the therapeutic effectiveness of paraprofessional counselors at the Hot Springs Rehabilitation Center in Arkansas. Clients were randomly assigned to one of three treatment groups: (1) a professional counselor working alone; (2) a professional counselor assisted by an aide who was given supervision, or (3) a counselor aide who functioned completely as the client's counselor but with supervision. Counselor performance was measured by: (1) the client's work quantity; (2) client cooperativeness; (3) client work attitude; (4) quality of client work; (5) client dependability; (6) client ability to learn; (7) and client progress. Also, ratings on the quality of counseling were collected from the field counselors who had referred their clients to the center.

It was found that the paraprofessional counselors working alone provided counseling as effective as, if not significantly better than, that provided by the professional counselors working alone. These aides produced significantly better results on three outcome measures: (1) work quantity; (2) work attitude; (3) dependability. They also produced more positive results on the other measures al though these differences were nonsignificant. The counselor plus aide condition had the poorest effects upon the clients. When the tape recorded counseling sessions were analyzed, it was suggested 
that the greater positive effects on client rehabilitation by the paraprofessionals working alone was due to the somewhat higher levels of warmth and empathy communicated to their clients.

Durlak (1971) has also cited other research on the comparative effectiveness of various levels of mental health workers with chronic schizophrenics (Anker \& Walsh, 1961; Appleby, 1963; Colare11i \& Siege1, 1966; Mendel \& Rapport, 1963), female adolescent delinquents (Cole, Oetting, \& Miskimin, 1969), alcoholics and their families (Covner, 1969), and marriage counselees (Harvey, 1964).

Durlak (1971, p. 72) has concluded that these preceding studies indicate that paraprofessional therapists have fared quite well in comparison to professional therapists. In six of the 13 studies, the paraprofessionals have achieved significantly superior therapeutic results compared to professionals; in the other studies, results for the two groups are similar. In not one of the 13 comparative studies reviewed by Durlak have professionals been found to be statistically significantly superior to paraprofessional workers.

In another comparative study not included in Durlak's review, Lamb and Clack (1974) exposed students to professional or student paraprofessional approaches to counseling service orientation. It was found that the effectiveness of orientation programs in acquainting students with and promoting usage of student counseling centers is not dependent on professional involvement. Students exposed to both orientations expressed equally positive immediate reactions, however, paraprofessional utilization resulted in more subsequent visits to the counseling center. Lamb and Clack (1974) stated that 
this finding is consistent with the rationale that student paraprofessionals lend greater credibility and accessibility than professionals to counseling services.

Grigg (1961) investigated how clients' reports differ when they express their reactions to counselors from three different levels of professional development. The reaction of clients to doctorat counseling psychologists, to counseling trainees who had completed a year's internship, and to inexperienced counseling trainees who had not yet completed an internship or practicum, were compared. The subjects used in this study consisted of 249 clients who received counseling at the University of Texas Testing and Counseling Center for two or more sessions. He concluded that there was no difference in clients' reports of favorableness of counseling outcomes by the three different levels of therapist experience.

In a study designed to investigate a number of issues, Truax (1965) compared the therapy paraprofessionals were providing to their clients to the therapy provided by graduate student trainees, and experienced counselors. The subjects consisted of 150 chronic hospitalized patients who were randomly assigned to the three different therapist groups. It was found that "the lay mental health counselors were able to provide a level of therapeutic conditions only slightly below that of the experienced therapists and considerably above that of graduate student trainees" (Truax, 1965, p. 9). Despite the voluminous evidence supporting the notion of clinical effectiveness for paraprofessional personnel, the praise is not universal nor is it without qualification. Of the 300 references 
concerning paraprofessionals identified by Durlak (1971), six reports were discovered that cited negative results. These should not be dismissed lightly. Unless controlled evaluative studies are undertaken to determine the specific situations in which paraprofessionals are most effective, the utilization of the mental health worker may be inappropriate.

Several authors have stated that the majority of the empirical paraprofessional literature is plagued with the methodological inadequacies characteristic of clinical studies in general. Gruver (1971) has found that fewer than 25 percent of the reports on paraprofessional counseling have compared experimental with control populations, used both pre and post assessment, or employed objective criteria. Lamb and LaFave (1975) have echoed the observation that college paraprofessionals are evaluated by objective measurements relatively infrequently.

Gruver adds that besides these problems there are few studies dealing specifically with college students as therapeutic agents, and that few of the available studies are similar enough in any respect to warrant conclusiveness in a given area. Consequently, he concludes that it is impossible to draw firm conclusions about the relative effectiveness of college students as therapeutic agents (Gruver, 1971). Similarly, Cowen (1973) has stated that a succinct, unequivocable summary on the paraprofessional movement is difficult. He adds that the summaries which are available in the literature are uncritical and rely too heavily on soft data and personal impressions from those individuals involved in the movement. 
Gartner (1971) has stated that although no one of the studies of paraprofessional effectiveness is conclusive by itself, several of them (such as those by Ellsworth, Truax, and Sobey) do offer rather powerful evidence. He continues that the "multiplicity of evidence derived from a great variety of sources, stemming from different methods and indexes, leads to the conclusion that paraprofessionals play an important role as treatment agents and contribute to the improved mental health of clients and patients in highly significant, often unique, ways" (Gartner, 1971, p. 52).

Clearly, as Cowen (1973) and others have suggested, an empirically sound evaluation is still needed before a reliable decision can be reached concerning the therapeutic effectiveness of paraprofessional personnel. One cannot find the answers if the questions are not asked.

\section{The College Paraprofessional}

Cowen (1973) has stated that college students have been in the forefront of the paraprofessional movement. Programs at Harvard University (Kantor \& Greenblatt, 1962; Umbarger, Dalsimer, \& Morrison, 1962) and the Connecticut Valley State Hospital (Holzberg, 1963; Holzberg, Knapp, \& Turner, 1967; Scheibe, 1965) utilized college students as companions to chronic psychiatric patients or lived with them in residential half-way houses.

A questionnaire administered to the patients at the Connecticut Valley Hospital yielded data suggesting that the program had positive effects on both the patients and students (Holzberg, Whiting, 
\& Lowy, 1964). Eighty-four percent of the patients said they enjoyed the relationship with the student paraprofessionals, while the students reported that 71 percent of the patients showed improvement over the year.

Lawton and Lipton (1963) have reported on a project at the Morristown State Hospital which employed six college students full time. No training was given, but the students were instructed to devote all their efforts to create highly personal relationships with individual patients.

College student involvement in this specific role is quite extensive. A study conducted early in this decade indicated that there were more than 500 such programs (Zax \& Cowen, 1972).

College paraprofessionals have worked with various age groups: Hunt (1969) has described a program in which college paraprofessionals worked with various child populations, all of which were experiencing adaptive problems. College students have been utilized in programs for hospitalized children (Kreitzer, 1969; Reinherz, 1963); children in outpatient clinic settings (Brennen, 1967; Davison, 1965); as play therapists (Linden \& Stollak, 1969; Stollak, 1969); institutionalized delinquents (Gorlich, 1967; Sarason \& Ganzer, 1969); children with school problems (Cowen, 1968; Cowen, Carlisle, \& Kaufman, 1969; Cowen, Zax, \& Laird, 1966); as well as counseling other college students.

Various investigators have used college students as "behavioral technicians" (Davison, 1965; Gelfard, Elton, \& Harmon, 1971; Patterson, Ray, \& Shaw, 1968) and the 1iterature is quite extensive. For example, Powell (1975) has described an undergraduate course 
offered at the University of Michigan entitled "Advanced Laboratory in Behavior Modification." Students spend six hours a week working with clients at various field placements. During this time the students and clients decide on the target behaviors to be modified, take baseline measures, define treatment goals, and institute specific treatment interventions. Treatment procedures include shaping behaviors, positive reinforcement, modeling, or assertiveness training. One hour per week is spent in supervision (Powe11, 1975). Powell has found the students enrolled in this practicum course to exhibit enthusiastic exuberance, positive attitude, and idealism. Powell adds that these characteristics help students to accomplish goals that an experienced professional might not have achieved because the latter's expectations may have been low. He also reports that his student paraprofessionals achieved complete success with 91 percent and 82.1 percent of their clients during the fall and winter semesters of the 1972-73 academic year, respectively.

Many other programs have used college paraprofessionals as behavior modification therapists. Johnson, Katz, and Gelfand (1972) have reported on the training and utilization of undergraduates as behavioral technicians on an adult token economy ward. Other authors have also concerned themselves with paraprofessional training in behavior modification procedures (Gardner, 1972; McGee \& Pope, 1975; Wasserman, McCarthy, \& Ferree, 1975; Aiken, Browne11, \& Iscoe, 1974; Panyan \& Patterson, 1974).

Paraprofessionals have been increasingly considered as a potential manpower source for the delivery of mental health service in the 
college community. For example, the Joint Commission on Mental I11ness and Health recommended that volunteer work by such paraprofessional groups as college students be encouraged and extended (Joint Commission on Mental Illness and Health, 1961).

Similarly, the consistency of his research results have led Brown (1974) to conclude that paraprofessional counseling is an effective, acceptable, practical, and adaptable counseling procedure for academic difficulties. Consequently, he recommended that educational institutions should consider adding paraprofessional personnel to their available counseling service (Brown, 1974).

These recommendations are not surprising considering the observation that "paraprofessionals seem to be most effective with clients who present problems of a situational or crisis nature. In general, these are the problems of normal young adults or returning students who are trying to cope and live within a university environment" (Aiken, Browne11, \& Iscoe, 1974, p. 485).

Indeed, it appears that these recommendations for paraprofessional utilization on the college campus have been acted on by a variety of professionals. A survey completed by Zunker and Brown (1966) indicated that college personnel programs are increasingly utilizing upperclassmen to assist in the early orientation of freshmen to the college community.

Lamb and LaFave (1975) have reported surveying various university counseling centers. One hundred nineteen counseling centers responded, representing all United States locations. Paraprofessionals were found to be utilized by 38 percent ( 45 centers) of the 
119 centers participating in the study.

These 45 centers reported an average of 3.7 different paraprofessional functions. The most frequently cited functions included: information disseminator $(17 \%)$, outreach activities (15\%), individual counseling without a professional staff member (13\%), and referral agent (13\%). Lamb and LaFave have suggested that college paraprofessionals are increasingly utilized in behavior modification programs such as anxiety reduction workshops.

\section{The Management of Test Anxiety}

Most of the literature on anxiety indicates that subjects with a high level of anxiety manifest higher levels of performance on simple learning tasks than do subjects with low anxiety scores (Spence \& Taylor, 1951; Spence \& Farber, 1953; Spence \& Beecroft, 1954). However, highly anxious subjects do not perform as effectively as low anxious subjects on complex tasks (Farber \& Spence, 1953; Montague, 1953; Taylor \& Spence, 1952).

Spielberger and his associates have studied the effects of high anxiety levels on academic success. They reported that highly anxious students receive lower grades and have a higher academic failure rate than less anxious students of equal intelligence (Spielberger, 1952; Spielberger \& Katzmeyer, 1959).

In addition, Wine (1971) has found that highly test-anxious persons typically perform more poorly on tests than do low test anxious persons. These effects are enhanced when the tests are stressful and are administered under evaluative conditions. Thus, 
i.t would appear that test anxiety treatment programs are needed to insure that students will profit as much as is possible from their academic experiences.

Recently, counseling programs have focused on the management of test anxiety in academic environments. Test anxiety appears to be relatively common among academic populations. It has been estimated that test anxiety occurs in from 3 percent to 90 percent of academic populations (Donner \& Guerney, 1969; Eysenck \& Rachman, 1965; Johnson \& Sechrest, 1968; Kondas, 1967).

Test anxiety has been defined as that condition which inhibits an individual's performance on tests which is not caused by lack of ability or knowledge. Test anxiety, whether it be rational or irrational, is experienced as a debilitating force which disrupts the capacity of the student, to concentrate, think and remember, and is generally accompanied by states of extreme tension, restlessness, and nausea (Mitchel1 \& Ingham, 1970).

Mandler and Sarason (1952) have presented an original theory of test anxiety. Their theory assumes that two types of drives are present in the test situation. The first type of drive is considered a learned task drive which is reduced by response sequences which terminate in the completion of the task. The second type of drive is a conditioned anxiety drive which can produce two classes of responses: (1) those related to task completion which reduce anxiety, and (2) those which compete with completion of the task. Mandler and Sarason (1952, p. 166) state that this second class of responses may be characterized by 
... feelings of inadequacy, helplessness, heightened somatic reactions, anticipations of punishment or loss of status and esteen, and implicit attempts at leaving the test situation. It might be said that those responses are self, rather than task-centered.

The first class of responses can be defined as facilitative in that they promote successful task resolution while the second class are defined as debilitative responses since they interfere with successful performances.

Wine (1971) found that the low test anxious person is focused by task-relevant variables in the test situation, while the high test anxious person is internally focused on self-evaluative, self-deprecatory thinking and awareness of his autonomic functioning. Test anxious persons cannot perform adequately since they divide their attention between internal and task cues.

Similarly, Marlett and Watson (1968) reported that the testanxious individual spends a proportion of his task time in things unrelated to the task. Test anxious persons may worry about their performance, worry about how others might do, ruminate over the available choices, and are often repetitive in their attempts to complete the task. They suggest that any effort to overcome these non-productive, inefficient behaviors should focus on permitting the test anxious $\mathrm{client}$ to perform without the consequences which enhance the adverse effects of the avoidance behaviors (Marlett \& Watson, 1968).

Many clinical techniques have been adapted to the treatment of test anxiety. Group-insight counseling and behavioral approaches are frequently cited in the literature (Kostka, 1974). 
Briefly, group-insight therapy has attempted to provide group members with insight into the dynamics of test-anxiety. Discussions of study skills and examination strategies are often included in this treatment.

Chestnut (1965) reviewed 15 studies in which group counseling procedures were used with academic underachievers whose test anxiety contributed significantly to their poor performance. Only two of the 15 studies were found to produce any positive changes.

Similarly, Mann (1969) concluded in his literature review that most clinicians using insight techniques have reported minimal or conditional therapeutic changes. These reports suggest only marginal effectiveness for insight-oriented procedures in reducing test anxiety.

Behavior therapy has provided various techniques for the treatment of test-anxious students, such as implosive techniques (Prochaska, 1971), overt positive reinforcement (Caute1a, 1970; Wisocki, 1970), and systematic desensitization procedures. Treatments utilizing systematic desensitization have provided the most widely successful approach to the treatment of test anxiety (Kostka, 1974).

Wolpe (1969, p. 91) defined systematic desensitization as . . the breaking down of neurotic anxiety-response habits in piecemeal fashion. A physiological state inhibiting of anxiety is induced in the patient who is then exposed to a weak anxiety-arousing stimulus. The exposure is repeated until the stimulus loses completely its ability to evoke anxiety.

Wolpe's technique consists of these components: (1) training in deep muscle relaxation according to the model of Jacobsen (1938); (2) the construction of anxiety eliciting simuli in hierarchies; 
(3) the gradual pairing in imagination of the anxiety-producing stimuli while muscular relaxation is present.

\section{Present Study}

The previously cited lines of research have demonstrated that the college paraprofessional represents an important mental health manpower source and can provide effective clinical services to the college community. However, for their potential to be fully realized, professional psychology must determine in what specific situations and under what conditions the college paraprofessional is able to provide effective psychotherapy.

As stated previously, test anxiety is a rather serious problem in academic communities, in terms of both incidence figures and its debilitating effect on scholastic achievement. It is possible that undergraduate paraprofessionals can provide effective treatment to test anxious students, because of their position in the college community, commonality of background and similar institutional experiences.

The purpose of the present study is to determine the relative effectiveness of professional and paraprofessional treatments in the group management of college students exhibiting test anxiety. Both groups of therapists provided similar clinical treatment to their clients. Treatment procedures included cognitive restructuring, deep muscle relaxation and systematic desensitization.

Previously cited lines of research have indicated superior clinical effectiveness on the part of paraprofessional therapists due to their lack of professional stance, personal characteristics, and 
ability to provide conditions conducive to therapy. Conversely, professional therapists possess more formal training, greater experience with various therapeutic techniques and a rigorous theoretical background. It was not known which therapist group would produce superior therapeutic gains in their test anxious clients.

Therefore it is hypothesized that the treatment groups will exhibit significant pre-post decreases in debilitating test anxiety as measured by the debilitating portion of the Alpert-Haber Achievement Anxiety Test (DAAT) and the State portion of the Speilberger State-Trait Anxiety Inventory (STAI-S). It is also hypothesized that there will be no significant pre-post difference between the two treatment groups as measured by the DAAT and the STAI-S. 
CHAPTER II

METHOD

\section{Subjects}

Subjects used in this study were 26 voluntary clients who participated in the Illinois State University Student Counseling Center Test Anxiety Workshops which were offered from October 1977 to May 1978. Originally the subject pool had consisted of $47 \mathrm{clients,} \mathrm{how-}$ ever, 21 students who did not attend at least 60 percent of al1 workshop sessions or who did not complete all instruments were eliminated from the study.

\section{Instruments}

The instruments used in this study were Spielberger's StateTrait Anxiety Inventory (STAI) (Spielberger, Gorusch, \& Lushene, 1970) and a modified version of Alpert and Haber's (1960) Achievement Anxiety Test (AAT).

The STAI is a forced-choice questionnaire consisting of 40 statements. It is comprised of separate self-report scales for measuring distinct anxiety concepts: State anxiety (A-State) and trait anxiety (A-Trait). The A-State and A-Trait subscales contain 20 statements each. Scores for the STAI range from a minimum score of 20 to a maximum score of 80 on both subscales. Subjects respond to each STAI item for both subscales by rating themselves on a fourpoint scale. The State subscale directions were modified by asking 
subjects to respond to how they would feel when taking a test (see Appendix A).

Normative data and a history of the development of the STAI are presented by Spielberger, Gorsuch, and Lushene (1970). The testretest correlations for the A-Trait scale were found to be reasonably high, ranging from .86 for males and .76 for females after a 20 day interval to .73 and .77 for males and females respectively after 104 days. Considering the transitory nature of anxiety states, measures of internal consistency such as the alpha coefficient would provide a more meaningful index of the reliability of A-State scales than test-retest correlations. Internal consistency coefficients (Alpha coefficients) for the A-State scale obtained, ranged from .83 to .92, and from .86 to .92 for the A-Trait scale. Further evidence of the internal consistency of the STAI scales is provided by item-remainder correlations computed for samples of high school and college students. The median A-State item-remainder correlation was .55 for the high school students, .45 for the college freshmen, and .55 for the college undergraduates. The corresponding A-Trait item-remainder correlations were $.54, .46$, and .53 , respectively.

Data for the construct validity of the A-State scale is available for a sample of 977 undergraduate college students at Florida State University. These students were first administered the A-State scale with the standard instructions (NORM condition). They were then asked to respond according to how they believed they would feel while taking an examination (EXAM condition). 
The mean scores in the NORM and EXAM conditions are reported for the 20 item A-State scale and for each individual item. Critical ratios for the differences between these means and point-biserial correlations are also reported. The degree to which each item reflected differences in A-State evoked by the two experimental conditions is indicated by the size of the critical ratios and by the magnitude of the point-biserial correlations. The mean scores for the A-State scale in the EXAM condition was reported to be 54.99 for the male subjects and 60.51 for the female subjects. The mean scores for the A-State scale in the NORM condition were reported to be 40.02 and 39.36 for the male and female subjects, respectively. The mean scores for the A-State scale were therefore found to be considerably higher in the EXAM condition than in the NORM condition for both males and females. In addition, all but one of the 20 items significantly discriminated between these conditions for the males, and all of the items were significantly higher in the EXAM condition for the females.

The AAT, developed by Alpert and Haber (1960) was modified for use at the Illinois State University Student Counseling Center by slightly altering the language of the items and rating scales, and the order of the item presentation being indicated on the five-point Likert scale (see Appendix B). Scores range from 1, almost never, to 5, almost always feeling in agreement with the item. The subjects answer each item indicating the degree to which the item applies to them. The AAT consists of two independent scales: a facilitating scale of 9 items based on a prototype of the item, "Anxiety helps me 
to do better during examinations and tests," and a debilitating scale of 10 items based on a prototype of the item, "Anxiety interferes with my performance during examinations and tests."

Normative data and the theoretical basis for the AAT are presented by Alpert and Haber (1960). Over an eight-month period, testretest reliability coefficients were obtained of .75 for the facilitating scale and .76 for the debilitating scale. Over a ten-week interval, they produced test-retest reliabilities of .83 and .87 , respectively (Alpert \& Haber, 1960). The AAT measures anxiety as a construct similar to that measured by Mandler and Sarason's Test Anxiety Scale (TAS) (Mandler \& Sarason, 1952). Alpert and Haber report a correlation of .64 between the debilitating AAT scale and the TAS (significant at the .01 alpha level), indicating considerable equivalence.

\section{Therapists}

Four therapists directed the test anxiety group sessions. Two paraprofessional therapists (one male and one female) and two professional therapists (both males) were utilized. Both paraprofessional therapists and the one professional therapist who was an advanced doctoral student in counseling psychology reviewed the group treatment procedures with the other professional therapist (who was a Ph.D. level clinical psychologist and had 11 years of experience using desensitization and other "behavioral" techniques) to insure a common understanding of the program. In addition, both paraprofessionals and the doctoral student professional participated 
in one workshop led by the other professional as part of their training.

The paraprofessionals used in the present study are an integral part of the Behavioral Management Programs available at Illinois State University. In 1972, the Student Counseling Center at I11inois State University initiated a paraprofessional program to assist university students with their problems. The paraprofessionals are undergraduate students housed in university residence halls. They are referred to as "Student Advisors" (SA's). The role of the SA paraprofessional is defined as being a campus information source, referral agent, and a peer counselor. The selection, training, and supervision of the paraprofessionals is the responsibility of the Student Counseling Center.

The student paraprofessionals participate in a rigorous selection procedure. Applications, recommendations, and various interview evaluations serve as the basis for the selection of the paraprofessionals. The six major criteria applied in the selection process include: interpersonal skill, motivation, entrepreneur orientation, grade point average, year in school, and flexibility and tolerance of different life styles.

The newly selected paraprofessionals participate in an eight day workshop immediately prior to the start of the fall semester where they receive basic training in information dissemination, referral procedures, and helping skills. The objectives of these workshops include: (1) the orientation of the new paraprofessionals to the Student Counseling Center, its broad objectives and their 
particular roles within that organization; and (2) to begin their training in both individual and group helping skills. The paraprofessionals are also involved in four hours of training and supervision per week throughout the academic year.

Information and referral training is accomplished primarily through didactic input by professional staff members, through small group discussions with experienced paraprofessionals, and familiarization with the S.A. Manual. Peer counseling skills training is accomplished through the use of a microcounseling training paradigm. Using this procedure, the paraprofessionals are instructed in the following skills: attending behavior, openended responding, minimal client encouragement, paraphrasing and reflection of feeling, goal setting, a sequence for decision-making and action planning.

The major components used in the training are skill description, modeling, video simulations, supervised role-playing, and feedback. Both professional staff and selected veteran paraprofessionals are used as trainer/supervisors in this process. The paraprofessionals also participate in a growth group experience structured to assist them in evaluating their strengths and weaknesses as helpers and to explore and develop strategies for improving as helpers.

\section{Procedure}

Training for students enrolled in the Test Anxiety Reduction Workshop groups consisted of five weekly one and one-half hour sessions and involved teaching students to better control and reduce their anxiety in examination situations. Clients were assisted in 
learning to identify situations in which they became anxious, learning to identify how they experience test anxiety (mentally and physically) so that they can become aware of these situations and learn to control their anxiety, as well as learning particular strategies for reducing their anxiety.

These skills were taught in five sessions which included: (a) a discussion of the nature of test anxiety, and relaxation and systematic desensitization training; (b) review of the first session, discussion of anxiety arousing and negative self-defeating statements, irrational beliefs, and anxiety inhibiting statements; (c) a review of negative self statements, development of anxiety inhibiting statements, discussion of an overall model for understanding and coping with test anxiety, review of the test anxiety hierarchy and systematic desensitization and practicing relaxation techniques; (d) a continuation of systematic desensitization; and (e) the completion of the systematic desensitization hierarchy.

Each Test Anxiety Workshop was 1ed by either the two paraprofessionals together or by one of the professional therapists. Subjects registered for the workshops according to standard Student Counseling Center procedures. An attempt was made to match the student's available time and the workshop schedule. Students were not informed of the group's leader(s) prior to registration.

Group leaders administered both the STAI and AAT at the beginning of the first and at the end of the last sessions of the Test Anxiety Workshops. Subjects who did not attend the last workshop session, but who had attended at least 60 percent of the sessions, 
were contacted by the author to complete the post measures as soon as was possible.

To test the hypothesis that both the professional and paraprofessional therapist groups will exhibit significant pre-post decreases in debilitating test anxiety as measured by the DAAT and the STAI-S, related samples $\underline{t}$ tests were used.

To test the hypothesis that there will be no significant prepost difference between the professional and paraprofessional therapist groups, analyses of covariance were used with the pre-DAAT and pre-STAI-S scores as the covariates and the post-DAAT and post-STAI-S scores as the criteria. 
CHAPTER III

RESULTS

The purpose of this study was to examine the relative effectiveness of professional and paraprofessional treatment in the group management of college students exhibiting test anxiety. Analyses of the results include overall decreases in debilitating test anxiety, decreases in debilitating test anxiety by therapist group, individual workshop differences, and workshop attrition rates.

\section{Overall Decreases in Debilitating Test Anxiety}

The first hypothesis predicted that both the professional and paraprofessional therapists' groups would exhibit significant pre-post decreases in debilitating test anxiety as measured by the STAI-S and the DAAT. Related samples $\underline{t}$-tests were performed on the FAAT data, as well as the DAAT and STAI-S data. These results are summarized in Table 1.

As shown in Table 1, clients who participated in workshops led by professional therapists achieved significant decreases on both the STAI-S and DAAT data. Clients who participated in workshops led by paraprofessional therapists achieved a significant decrease on the DAAT measure only. 
TABLE 1

PRE AND POST MEAN TEST ANXIETY SCORES

\begin{tabular}{ll|r|l|l|l|r|r|r}
\hline \hline Measure & Group & $n$ & Pre & $\underline{\text { SD }}$ & Post & $\underline{\text { SD }}$ & $\underline{\text { df }}$ & $\underline{\mathrm{t}}$ \\
\hline \multirow{2}{*}{ STAI-S } & Professional & 19 & 55.58 & 12.15 & 46.79 & 11.80 & 18 & $2.99^{*}$ \\
& Paraprofessional & 7 & 55.86 & 15.93 & 52.29 & 7.25 & 6 & 0.62 \\
DAAT & Professional & 19 & 33.32 & 6.10 & 28.42 & 6.37 & 18 & $4.00^{* * *}$ \\
& Paraprofessional & 7 & 35.14 & 5.37 & 30.86 & 4.26 & 6 & $4.42^{* *}$ \\
FAAT & Professional & 19 & 21.11 & 5.13 & 22.11 & 5.70 & 18 & -0.92 \\
& Paraprofessional & 7 & 17.86 & 3.44 & 19.57 & 3.21 & 6 & -1.58 \\
\hline \hline
\end{tabular}

\footnotetext{
${ }^{*} \mathrm{p}<.05$

$* * p<.01$

$* \star * p<.001$
}

Decreases $\frac{\text { in }}{\text { by }}$ Debilitating $\frac{\text { Test }}{\text { Therapist Group }}$ An

The second hypothesis predicted that there would be no significant pre-post differences between the two treatment groups as measured by the STAI-S and DAAT. Analyses of covariance were performed on the data with pre-STAI-S, pre-DAAT, and pre-FAAT scores as the covariates and post-STAI-S, post-DAAT and post-FAAT scores as the criteria. Mean and adjusted post-mean test anxiety scores are shown in Table 2.

No significant differences were found in the decreases for debilitating test anxiety or for the increases in facilitating test anxiety between the professional and paraprofessional therapists' groups. These results are summarized in Tables 3 and 4. 
TABLE 2

MEAN AND ADJUSTED POST-MEAN TEST ANXIETY SCORES

\begin{tabular}{llrccccc}
\hline \hline Measure & Group & $\mathrm{n}$ & Pre & Post & $\begin{array}{c}\text { Adjusted } \\
\text { Post }\end{array}$ & $\mathrm{F}$ & \\
\hline \multirow{2}{*}{ STAI-S } & Professional & 19 & 55.58 & 46.79 & 46.81 & 1.43 & NS \\
& Paraprofessional & 7 & 55.86 & 52.29 & 52.22 & & \\
\multirow{2}{*}{ DAAT } & Professional & 19 & 33.32 & 28.42 & 28.75 & 0.37 & NS \\
& Paraprofessional & 7 & 35.14 & 30.86 & 29.96 & & \\
FAAT & Professional & 19 & 21.11 & 22.11 & 21.51 & 0.03 & NS \\
& Paraprofessional & 7 & 17.86 & 19.57 & 21.18 & & \\
& & & & & & & \\
\hline \hline
\end{tabular}

TABLE 3

ANALYSES OF COVARIANCE FOR DECREASES IN DEBILITATING TEST ANXIETY BETWEEN PROFESSIONAL AND

PARAPROFESSIONAL THERAPISTS' GROUPS

\begin{tabular}{|c|c|c|c|c|c|c|}
\hline Measure & Source & & $\underline{\text { SS }}$ & MS & df & $\underline{F}$ \\
\hline STAI-S & $\begin{array}{l}\text { Groups } \\
\text { Within Groups } \\
\text { Total }\end{array}$ & $\begin{array}{l}\text { (Adj.) } \\
(\operatorname{Adj.} .) \\
(\operatorname{Adj} .)\end{array}$ & $\begin{array}{r}149.61 \\
2402.88 \\
2552.49\end{array}$ & $\begin{array}{l}149.61 \\
104.47 \\
106.35\end{array}$ & $\begin{array}{r}1 \\
23 \\
24\end{array}$ & 1.43 NS \\
\hline DAAT & $\begin{array}{l}\text { Groups } \\
\text { Within Groups } \\
\text { Total }\end{array}$ & $\begin{array}{l}\text { (Adj.) } \\
(\operatorname{Adj} .) \\
(\operatorname{Adj} .)\end{array}$ & $\begin{array}{r}7.33 \\
460.41 \\
467.74\end{array}$ & $\begin{array}{r}7.33 \\
20.02 \\
19.49\end{array}$ & $\begin{array}{r}1 \\
23 \\
24\end{array}$ & $.366 \mathrm{NS}$ \\
\hline
\end{tabular}


TABLE 4

ANALYSIS OF COVARIANCE FOR INCREASES IN FACILITATING TEST ANXIETY BETWEEN PROFESSIONAL AND

PARAPROFESSIONAL THERAPISTS' GROUPS

\begin{tabular}{llccccc}
\hline \hline Source & & $\underline{\text { SS }}$ & $\underline{\underline{M S}}$ & $\underline{\mathrm{df}}$ & $\underline{\mathrm{F}}$ \\
\hline & & & & & & \\
Groups & (Adj.) & 0.492 & 0.49 & 1 & 0.029 & NS \\
Within Groups (Adj.) & 393.66 & 17.12 & 23 & & \\
Total & (Adj.) & 394.15 & 16.42 & 24 & & \\
\hline
\end{tabular}

For additional analysis, the professional therapists' group was divided into two different groups based on the amount of professional experience. When these two groups were compared with the paraprofessional therapists' group, no significant differences were found. However, it was found that the pre-post mean differences measuring therapeutic gains generally increased as the therapist(s)' experience increased, as shown in Table 5 .

\section{TABLE 5}

TEST ANXIETY PRE-POST MEAN DIFFERENCES BY THERAPIST EXPERIENCE ${ }^{a}$

\begin{tabular}{lrrrrr}
\hline \hline \multirow{2}{*}{ Therapist Experience } & $n$ & \multicolumn{4}{c}{ Mean differences } \\
\hline Doctoral-level professional & 4 & 13.75 & 5.75 & 2.00 \\
Doctoral-student professional & 15 & 7.46 & 4.67 & -1.80 \\
Undergraduate paraprofessional & 7 & 3.57 & 4.28 & -1.71 \\
\hline \hline
\end{tabular}

aAll differences between therapist groups were nonsignificant. 
Individual Workshop Differences

Analyses of covariance were performed on the data for each individual workshop with pre-STAI-S, pre-DAAT, and pre-FAAT scores as the covariates and post-STAI-S, post-DAAT and post-FAAT scores as the criteria. Since only one subject was used from the first paraprofessional workshop, subjects from the first and second paraprofessional workshops were combined together. F-ratios of 0.68 , .96 , and 1.83 were obtained from the STAI-S, DAAT, and FAAT data, respectively. No significant differences between the four individual test anxiety workshops were observed.

\section{Workshop Attrition Rates}

Of 47 original subjects, only 26 subjects were utilized in the study. Only those subjects who attended at least three sessions were used. Workshop attrition rates were analyzed as an additional measure of therapist effectiveness. Completely accurate attendance records were not available for four subjects enrolled in the paraprofessionals' first workshop. However, it was known that these subjects attended either one or two workshop sessions. Consequently, a mean of 1.5 sessions attended was used as the attendance data for each of these four subjects.

It was found that clients who participated in workshops led by professional and paraprofessional therapists attended a mean of 3.45 and 2.94 sessions, respectively. The difference between these means was not significant. 
CHAPTER IV

DISCUSSION

The purpose of this study was to examine the relative effectiveness of professional and paraprofessional treatment in the group management of college students exhibiting test anxiety. The results discussed include overall decreases in debilitating test anxiety, decreases in debilitating test anxiety by therapist groups and workshop attrition rates.

\section{Overall Decreases in Debilitating Test Anxiety}

It was hypothesized that both the professional and paraprofessional therapists' groups would exhibit significant pre-post decreases in debilitating test anxiety as measured by the STAI-S and the DAAT. As expected, both therapist groups exhibited significant decreases in test anxiety after participating in the Student Counseling Center's Test Anxiety Workshops, substantiating this hypothesis. Clients who participated in workshops led by a professional therapist achieved significant reductions in debilitating test anxiety on both the STAI-S and DAAT measures. Clients participating in the paraprofessional therapists' workshops achieved a significant decrease on the DAAT only. However, the STAI-S means did decrease between the pre- and postmeasures indicating less anxiety as predicted. These results are similar to the finding that paraprofessional therapists can effectively administer covert positive reinforcement and systematic desensitization 
treatments to test anxious clients (Kostka, 1974).

One possible explanation concerning the failure to find a significant decrease on the STAI-S data for the paraprofessional therapists' group involves the small subject population used in the study. Only seven subjects who participated in the test anxiety workshops led by the paraprofessional therapists attained the criterion of 60 percent attendance (three sessions) of the workshop sessions and completed the necessary instruments.

Extremely large differences are needed to detect statistical significance with a population of seven subjects. In addition, a small subject population is sensitive to extreme scores. One subject in the paraprofessionals' group did exhibit such extreme scores, as shown in Appendix C. This subject attained STAI-S pre and post scores of 25 and 52 , respectively, indicating an increase in debilitating test anxiety. The DAAT and FAAT difference scores for this subject were in the appropriate direction. Perhaps as Kostka (1974) has stated, the DAAT with its fewer items, its limited range and smaller standard deviation, is more prone to reflect statistically significant changes in anxiety than other test anxiety instruments. It is interesting to speculate on whether a larger subject population for the paraprofessional therapists' group would have produced a significant decrease on the STAI-S test anxiety measure also.

The FAAT data did not indicate significant differences for either the professional or paraprofessional therapists' groups. This finding is consistent with the text anxiety literature which utilized the FAAT. Mitchell and Ingham (1970) failed to obtain significant 
changes in the FAAT data. Similarly, Prochaska (1970) and Johnson and Sechrest (1968) failed to produce changes in FAAT scores.

This difficulty in changing FAAT scores may be due to the fact that the effects of these treatments are specific to debilitating test anxiety and not facilitating test anxiety. This explanation is not surprising considering the nature of the test anxiety workshops and the notion of facilitating test anxiety. The Test Anxiety Workshops offered at the Student Counseling Center were focused on assisting clients in identifying situations in which they become anxious, learning to identify how they experience test anxiety, and learning to control and reduce their anxiety. These goals were accomplished through the use of: (1) cognitive modification of anxiety arousing and negative self-defeating statements and irrational beliefs; (3) development of anxiety inhibiting statements; and (3) relaxation techniques and systematic desensitization. These activities were specifically focused on decreasing clients' debilitating test anxiety (i.e., anxiety which interferes with performance during examinations). Facilitating test anxiety has been defined by Alpert and Haber (1960) as anxiety that helps an individual's performance during examinations and is measured by the FAAT. FAAT data was analyzed as an additional measure of therapist effectiveness although no overt attempt was made during the workshops to increase the participants' facilitating test anxiety. 


\section{$\frac{\text { Decreases }}{\text { Anxiety }} \frac{\text { in }}{\text { by }} \frac{\text { Debilitating Test }}{\text { Therapist Group }}$}

The hypothesis that there would be no significant pre-post difference between professional and paraprofessional therapists' groups was substantiated for the STAI-S, DAAT, and FAAT data. No trend toward significance was detected. Therefore, it is concluded that college student paraprofessionals compare favorably to professional therapists in the group management of test anxiety and consequently represent a potential manpower resource for the delivery of these services in the academic community. This conclusion is consistent with the previously cited literature concerning paraprofessional effectiveness being equal or superior to professional mental health workers in providing various therapeutic functions.

However, this conclusion cannot be made without qualification. As previously mentioned, the study was hampered by a small subject population. Differences between the two therapist groups would have to be extremely large to be observed.

Two possible explanations of the comparable effectiveness between the professional and paraprofessional therapists concern the qualities both groups of therapists bring to the therapeutic encounter. It has been previously stated that the paraprofessionals' clinical effectiveness is due to their lack of professional stance, personal characteristics (i.e., therapist-offered conditions), and similarity of background to the client, while professional therapists possess more formal training, greater experience with various therapeutic techniques, and a rigorous theoretical background. Perhaps these 
respective qualities balanced in some manner, producing similar therapeutic gains for clients in both the professional and paraprofessional therapists' groups. A more parsimonious explanation is that the salient variables (technical skills, therapist-offered conditions, etc.) in producing therapeutic gains for the test anxious clients were equally distributed between the professional and paraprofessional therapists.

\section{Workshop Attrition Rates}

It was found that the professional therapists' group attained a mean of 3.45 sessions attended which was greater than a mean of 2.94 sessions attended by the paraprofessional therapists' group. The difference between these means was not significant, indicating that attrition from both therapist groups was similar.

\section{Limitations of the Study and Future Research}

There were a number of weaknesses inherent in the design of this study. The small subject population has already been mentioned. Future research might avoid this limitation by actively recruiting subjects through wider advertising on campus of the Test Anxiety Workshops (expanded campus newspaper and radio exposure, residence hall notices, etc.).

Another limitation to consider regards the lack of an experimental control group. Consequently, it cannot be stated with complete conviction that the beneficial changes that occurred over the length of the workshops were the result of factors intrinsic to the workshops. It is possible that the workshop participants were able to cope more 
effectively with their test anxiety as a result of other events.

Some experimental rigor was lost since this study used subjects that could not be randomly assigned to the two different treatment groups. Subject assignment had to be made on the basis of the subject's schedule. However, subjects were not informed of the group's leader(s) prior to registration.

Another limitation of the study concerns the use of selfreported test anxiety measures only. Consequently, it is possible that differences between reported and actual test anxiety or examination performance were present.

In addition, there were differences in the composition of the two treatment groups. Both the sex and number of therapists varied. The paraprofessional therapists' workshops were led by two therapists (one male and one female), while the professional therapist's workshops were led by a lone therapist (one of two males).

Future research might assign interested students to either the professional or paraprofessional therapist group on a random basis provided their schedules permit. Students who contact the Student Counseling Center after the capacity of each workshop has been achieved could be placed on a waiting list and function as the control group. Their workshop participation would begin when the Behavioral Management Team offered the next workshop.

In summary, suggestions for further research are:

1. Future research might actively recruit subjects through wider campus advertising.

2. Future research might assign workshop participants to either the professional or paraprofessional therapists' group on a random basis. 
3. Future research might utilize a waiting list control group.

4. Future research might hold constant the sex and number of therapists in each treatment group.

5. Future research might compare actual examination performance before and after workshop participation for both professional and paraprofessional therapist groups.

6. Future research might compare actual examination performance and self-reported test anxiety.

7. Future research might investigate the therapeutic gains in test anxious clients with multiple levels of therapist experience.

8. Future research might investigate the effects of the test anxiety workshops over time to determine the stability of changes for the participants.

In summary, as expected it was found that both professional and paraprofessional therapists were effective in the group management of college students exhibiting test anxiety. As expected, no significant differences in effectiveness were found between the professional and paraprofessional therapists. This result is consistent with the literature concerning paraprofessional effectiveness in a variety of therapeutic situations. Further research may be able to overcome the limitations of this study and confirm the paraprofessionals' therapeutic effectiveness in the group management of test anxiety. 
REFERENCES 


\section{REFERENCES}

Aiken, J., Brownell, A., \& Iscoe, I. The training and utilization of paraprofessionals in a college psychological service center. Journal of College Student Personnel, 1974, 15, 480-486.

Albee, G. W. Conceptual models and manpower requirements in psychology. American Psychologist, 1968, 23, 317-320.

Allen, D. A. Peer counseling and professional responsibility. Journal of the American College Health Association, 1973, 21, 339-342.

Alpert, R., \& Haber, R. N. Anxiety in academic achievement situations. Journal of Abnormal and Social Psychology 1960, 61, 207-215.

Anker, J. M., \& Walsh, R. P. Group psychotherapy, a special activity program, and group structure in the treatment of chronic schizophrenics. Journal of Consulting Psychology, 1961, 25, 476-481.

Appleby, L. Evaluation of treatment methods for chronic schizophrenia. Archives of General Psychiatry, 1963, ㅇ, 8-21.

Arnhoff, F. N., Jenkins, J. W., \& Speisman, J. C. The new mental health workers. In F. N. Arnhoff, E. A. Rubinstein, \& J. C. Speisman (Eds.), Manpower for mental health. Chicago: Aldine, 1969.

Baker, E. J. The mental health associate: One year later. Community Mental Health Journal, 1973, 9, 203-214.

Bartels, B. D., \& Tyler, J. D. Paraprofessionals in the community mental health center. Professional Psychology, 1975, $\underline{6}, 442-452$.

Beck, J. C., Kantor, D., and Gelineau, V. A. Follow-up study of chronic psychotic patients "treated" by college case-aide volunteers. American Journal of Psychiatry, 1963, 120, 269-271.

Bergin, A. E. Some implications of psychotherapy research for therapeutic practice. Journal of Abnormal Psychology, 1966, 71, 235246.

Bergin, A. E., \& Jaspers, L. G. Correlates of empathy in psychotherapy: A replication. Journal of Abnormal Psychology, 1969, 74, 477-481.

Bergin, A. E., \& Solomon, S. Personality and performance correlates of empathetic understanding in psychotherapy. In T. Toml inson \& J. Hart (Eds.), New directions in client-centered therapy. Boston: Houghton-Mifflin, 1968. 
Bloom, B. L. Community mental health. Monterey, Ca.: Brooks-Cole, 1977.

Brennen, E. C. College students and mental health programs for children. American Journal of Public Health, 1967, 57, 1767-1771.

Brown, W. F. Student to student counseling: An approach to motivating academic achievement. Austin, Texas: University of Texas, Hogg Foundation for Mental Health, 1972.

Brown, W. F. Effectiveness of paraprofessionals: The evidence. Personnel and Guidance Journal, 1974, 53, 257-263.

Carkhuff, R. R. Training in the counseling and therapeutic practices: Requiem or reveille? Journal of Counseling Psychology, 1966, 13, $360-367$.

Carkhuff, R. R. Differential functioning of lay and professional helpers. Journal of Counseling Psychology, 1968, 15, 117-126.

Carkhuff, R. R. Helping and human relations. (Vols. I \& 2) New York: Holt, Rinehart \& Winston, 1969.

Carkhuff, R. R., \& Truax, C. B. Lay mental health counseling: The effects of lay group counseling. Journal of Consulting Psychology, $1965,29,426-431$.

Carson, R. C. A and B therapist "types": A possible critical variable in psychotherapy. Journal of Nervous and Mental Diseases, 1967, 144, 47-54.

Cautela, J. R. Covert reinforcement. Behavior Therapy, 1970, 1, 33-50.

Chestnut, W. J. The effects of structured and unstructured group counse1ing on male college students' underachievement. Journal of Counseling Psychology, 1965, 12, 388-394.

Colarelli, N. J., \& Siegel, S. M. Ward $H$ : An adventure in innovation. Princeton, New Jersey: Von Nostränd, T966.

Cole, C. W., Oetting, E. R., \& Miskimin, R. W. Self-concept therapy for adolescent females. Journal of Abnormal Psychology, 1969, 74, 642-645.

Cannon, J. R., \& Carkhuff, R. R. Effects of rater level of functioning and experience upon the discrimination of facilitative conditions. Journal of Consulting and Clinical Psychology, 1969, 33, 189-194.

Covner, B. J. Screening volunteer alcoholism counselors. Quarterly Journal of Studies on Alcohol, 1969, 30, 420-425. 
Cowen, E. L. The effectiveness of secondary prevention programs using nonprofessionals in the school setting. Proceedings of the 76th Annual Convention of the American Psychological Association, 1968, $3,705-706$.

Cowen, E. L. Social and community interventions. Annual Review of Psychology, 1973, 24, 423-472.

Cowen, E. L., Carlisle, R. L., \& Kaufman, G. Evaluation of a college student volunteer program with primary graders experiencing school adjustment problems. Psychology in the Schools, 1969, $\underline{6}, 371-375$.

Cowen, E. L., Zax, M., \& Laird, J. D. A college student volunteer program in the elementary school setting. Community Mental Health Journal, 1966, 2, 319-328.

Cowne, L. J. Approaches to the mental health manpower problem: A review of the literature. Mental Hygiene, 1969, $\underline{53}, 176-187$.

Crisler, J. R. Effective paraprofessional utilization: Myth or reality. Journal of Applied Rehabilitation Counseling, 1973, 4, $41-46$.

Crowe, M. J. The effectiveness of paraprofessionally-run social skills training groups for psychiatric inpatients (Doctoral dissertation, University of Georgia, 1975). Dissertation Abstracts International, 1976, 36, 6375-B. (University Microfilms No. 76-14,001, 123)

Davison, G. C. The training of undergraduates as social reinforcers for autistic children. In L. P. U17mann \& L. Krasner (Eds.), Case studies in behavior modification. New York: Holt, Rinehart \& Winston, 1965.

Deane, W. N. Intellectual stimulation for chronic schizophrenics. Mental Hospitals, 1960, 11, 45-46.

Deane, W. N., \& Ansbacker, H. L. Attendant-patient commonality as a psychotherapeutic factor. Journal of Individual Psychology, $1962,18,157-167$.

Donner, L., \& Guerney, B. G., Jr. Automated group desensitization for test anxiety. Behavior Research and Therapy, 1969, 7, 1-13.

Durlak, J. A. The use of nonprofessionals as therapeutic agents: Research, issues and implications. (Doctoral dissertation, Vanderbilt University, 1973). Dissertation Abstracts International, 1971, 32, 2999B-3000B. (University Microfilms No. $71-29,298)$ 
Durlak, J. A. Myths concerning the nonprofessional therapist. Professional Psychology, 1973, 4, 300-304.

Ellsworth, R. B. Nonprofessionals in psychiatric rehabilitation. New York: Appleton-Century-Crofts, 1968.

Engelkes, J. R., \& Roberts, R. R. Rehabilitation counselor's level of training and job performance. Journal of Counseling Psychology, $1970, \underline{17}, 522-566$.

Eysenck, H. J., \& Rachman, S. The causes and cures of neurosis. London: Routledge \& Kegan Paul, $\overline{1965}$.

Farber, I. E., \& Spence, K. W. Complex learning and conditioning as a function of anxiety. Journal of Experimental Psychology, 1953, $\underline{45}, 120-125$.

Felton, G. S., Wallach, H. F., \& Gallo, C. L. New roles for newprofessional mental health workers: Training the patient advocate, the integrator, and the therapist. Community Mental Health Journal, 1974, 10, 52-65.

Gardner, J. M. Teaching behavior modification to nonprofessionals. Journal of Applied Behavior Analysis, 1972, 5, 517-521.

Gartner, A. Do paraprofessionals improve human services: A first critical appraisal of the data. New York: New York University, 1969.

Gartner, A. Paraprofessionals and their performance. New York: Praeger, 1971 .

Gartner, A., Nixon, R., \& Riessman, F. (Eds.). Public service employment. New York: Praeger, 1973.

Gartner, A., \& Riessman, F. Paraprofessional movement in perspective. Personnel and Guidance Journal, 1974, 53, 253-256.

Gelfand, D. M., Elton, R., \& Harmon, R. E. A video feedback training method to teach behavior modification skills to nonprofessionals. Paper presented at the meeting of the Western Psychological Association, San Francisco, April 1971.

Gordon, J. Project cause: The federal anti-poverty program and some implications of subprofessional training. American Psychologist, $1965, \underline{20}, 334-343$.

Gorlich, E. H. Volunteers in institutions for delinquents. Children, $1967,14,147-150$.

Grigg, A. E. Client responses to counselors at different levels of experience. Journal of Counseling Psychology, 1961, ․ 217-222. 
Gruver, G. G. College students as therapeutic agents. Psychological Bulletin, 1971, 76, 111-127.

Harvey, L. V. The use of nonprofessional auxiliary counselors in staffing a counseling service. Journal of Counseling Psychology, $1964,11,348-351$.

Hawkins, R. P., Peterson, R. F., Schweid, E., \& Bijou, S. W. Behavior therapy in the home: Amelioration of problem parent-child relations with the parent in a therapeutic role. Journal of Experimental Child Psychology, 1966, 4, 99-107.

Hoch, E. L., Ross, A. 0., \& Winder, C. L. Conference on the professional preparation of clinical psychologists. American Psychologist, $1965,21,42-51$.

Hobbs, N. Mental health's third revolution. American Journal of Orthopsychiatry, 1964, 34, 822-833.

Holzberg, J. D. The companion program: Implementing the manpower recommendations of the joint commission of mental illness and health. American Psychologist, 1963, 18, 224-226.

Holzberg, J. D., Knapp, R. H., \& Turner, J. L. College student as companions to the mentally i11. In E. L. Cowen, E. A. Gardner, \& M. Zax (Eds.), Emergent approaches to mental health problems. New York: Appleton, Century \& Crofts, 1967.

Holzberg, J. D., Whiting, H. S., \& Lowy, D. G. Chronic patients and a college companion program. Mental Hospitals, 1964, 15, 152-158.

Hunt, J. M. Message, potpourri, and the Hall-Nebraska "model". The Clinical Psychologist, 1969, 22, 127-136.

Jacobson, E. Progressive relaxation. Chicago: University of Chicago Press, 1938.

Johnson, C. A., Katz, R. C., \& Gelfand, S. Undergraduates as behavioral technicians on an adult token economy ward. Behavior Therapy, $1972, \underline{3}, 589-592$.

Johnson, S. M., \& Sechrest, L. Comparison of desensitization and progressive relaxation in treating test anxiety. Journal of Consulting and Clinical Psychology, 1968, 32, 280-286.

Joint Commission on Mental Illness and Health. Action for mental health. New York: Basic Books, 1961.

Kalafat, J., \& Boroto, D. R. The paraprofessional movement as a paradigm community psychology endeavor. Journal of Community Psychology, $1977, \underline{5}, 3-12$. 
Kantor, D., \& Greenblatt, M. Wellmet: Halfway to community rehabilitation. Mental Hospitals, 1962, 13, 146-152.

Kondas, 0 . Reduction of examination anxiety and "stage-fright" by group desensitization and relaxation. Behavior Research and Therapy, $1967, \underline{5}, 275-281$.

Korman, M. Major themes of the conference. In M. Korman (Ed.), Levels and patterns of professional training in psychology. Washington, D.C.: American Psychological Association, 1976.

Kostka, M. P. A. The effectiveness of group systematic desensitization versus covert positive reinforcement as utilized by paraprofessionals in the reduction of test anxiety in college students (Doctoral dissertation, West Virginia University, 1973). Dissertation Abstracts International, 1974, 34, 4747A. (University Microfi Tms No. 74-202, 238)

Kreitzer, S. F. College students in a behavior therapy program with hospitalized emotionally disturbed children. In B. G. Guerney, Jr. (Ed.), Psychotherapeutic agents: New roles for nonprofessionals, parents and teachers. New York: Holt, Rinehart \& Winston, 1969.

Lamb, D. H., \& Clack, R. J. Professional vs. paraprofessional approaches to orientation and subsequent counseling contacts. Journal of Counseling Psychology, 1974, 21, 61-65.

Lamb, D. H., \& LaFave, F. E. Utilization of paraprofessionals in college counseling centers: A national survey. Paper presented at the meeting of the American Psychological Association, Chicago, September 1975.

Lawton, M. P., \& Lipton, M. B. Student-employees become companions to patients. Mental Hospitals, 1963, 14, 550-556.

Linden, J. I., \& Stollak, G. E. The training of undergraduates in play techniques. Journal of Clinical Psychology, 1969, 25, 213-218.

Magoon, T. M., \& Golann, S. E. Non-traditionally trained women as mental health counselors-psychotherapists. Personnel and Guidance Journal, 1966, 44, 788-793.

Maierle, J.P. The politics of supporting paraprofessionals. Professional Psychology, 1973, $4,313-320$.

Mandler, G., \& Sarason, S. B. A study of anxiety and learning. Journal of Abnormal and Social Psychology, 1952, 47, 166-173.

Mann, J. A comparison of the effects of direct versus vicarious individual and group desensitization of test-anxious students. UnpubTished masters thesis, University of Arizona, 1969. 
Marlett, N. J., \& Watson, D. Test anxiety and immediate or delayed feedback in a test-like avoidance task. Journal of Personality and Social Psychology, 1968, 8, 200-203.

McGee, J. P., \& Pope, B. Baccalaureate program for mental health workers. Professional Psychology, 1975, $\underline{6}, 80-87$.

Mende1, W. M., \& Rapport, S. Outpatient treatment for chronic schizophrenic patients: Therapeutic consequences of an existential view. Archives of General Psychiatry, 1963, $\underline{8}$, 190-196.

Mitchell, K. R., \& Ingham, R. J. The effects of general anxiety on group desensitization of test anxiety. Behavior Research and Therapy, $1970, \underline{8}, 69-78$.

Montague, E. K. The role of anxiety in serial rote learning. Journal of Experimental Psychology, 1953, 45, 91-96.

Opplinger, S. A network of volunteers for community programs. Hospital and Community Psychiatry, 1971, 22, 111-112.

Panyan, M. C., \& Patterson, E. T. Teaching attendants the applied aspects of behavior modification. Mental Retardation, 1974, 12, $30-32$.

Patterson, G. R., Ray, R. S., \& Shaw, D. A. Direct intervention in families of deviant children. Oregon Research Institute Bulletin, $1968,1-60$.

Persons, R. W., Clark, C., Persons, M., Kadish, M., \& Patterson, W. Training and employing undergraduates as therapists in a college counseling service. Professional Psychology, 1973, 4, 170-178.

Platman, S. R., Dorgan, R. E., \& Gerhard, R. J. Some social and political ramifications of utilizing non-physicians as chemotherapists. International Journal of Social Psychiatry, 1974-1975, 21, 65-69.

Poser, E. G. The effects of therapists' training on group therapeutic outcome. Journal of Consulting Psychology, 1966, 30, 283-289.

Powe11, D. R. Behavior modification: Students as paraprofessionals. Journal of Biological Psychology, 1975, 17, 19-25.

Prochaska, J. 0. Symptom and dynamic cues in the implosive treatment of test arxiety. Journal of Abnormal Psychology, 1971, 77, 133-142.

Reiff, R., \& Riessman, F. The indigenous nonprofessional: A strategy of change in community action and conmunity mental health programs. Community Mental Health Journal, 1965. (Monograph No. 1) 
Reinherz, H. College student volunteers as case-aides in a state hospital for children. American Journal of Orthopsychiatry, $1963,33,544-546$.

Rioch, M. J. Changing concepts in the training of therapists. Journal of Consulting Psychology, 1966, 30, 290-292.

Rioch, M. J., Elkes, C., Flint, A. A., Usdansky, B. S., Newman, R. G., \& Silber, E. National Institute of Mental Health pilot study in training mental health counselors. American Journal of Orthopsychiatry, 1963, 33, 678-689.

Roe, A., Gustad, J. W., Moore, G. U., Ross, S., \& Skodak, M. Graduate education in psychology. Washington, D.C.: American Psychological Association, 1959.

Rogers, C. R. Client-centered therapy. Boston: Houghton Mifflin, 1951.

Rogers, C. R. The necessary and sufficient conditions of therapeutic personality change. Journal of Consulting Psychology, 1957, 21, 95-103.

Sarason, I. G., \& Granzer, V. J. Social influence techniques in cliniCal and community psychology. In C. D. Spielberger (Ed.), Current topics in clinical and community psychology (Vol. 1). New York: Academic Press, $196 \overline{9}$.

Scheibe, K. E. College students spend eight weeks in mental hospital: A case report. Psychotherapy: Theory, Research and Practice, $1965,2,117-120$.

Scheur, J. H. Foreword. In C. Grosser, W. E. Henry, J. G. Kelly (Eds.), Nonprofessionals in the human services. San Francisco: JosseyBass, 1969.

Sobey, F. The nonprofessional revolution in mental health. New York: Columbia University Press, 1970.

Schofield, W. Psychotherapy: The purchase of friendship. Englewood Cliffs, New Jersey: Prentice-Hall, $1 \overline{96} 4$.

Spence, K. W., \& Beecroft, R. S. Differential conditioning and level of anxiety. Journal of Experimental Psychology, 1954, 48, 399-403.

Spence, K. W., \& Farber, I. E. Conditioning and extinction as a function of anxiety. Journal of Experimental Psychology, 1953, 45, 116-119.

Spence, K. W., \& Taylor, J. Anxiety and strength of the UCS as determiners of the amount of eyelid conditioning. Journal of Experimental Psychology, 1951, 42, 183-188. 
Spielberger, C. D. The effects of manifest anxiety on the academic achievement of college students. Mental Hygiene of New York, $1952, \underline{46}, 420-426$.

Spielberger, C. D., Gorsuch, R. L., \& Lushene, R. E. STAI manual for the state-trait anxiety inventory. Palo Alto, Ca.: $\overline{\text { Consulting }}$ Psychologists Press, 1970.

Spielberger, C. D., \& Katzenmeyer, W. G. Manifest anxiety, intelligence, and college grades. Journal of Consulting Psychology, $1959, \underline{23}, 278$.

Steele, R. L. A manpower resource for community mental health centers. Journal of Community Psychology, 1974, 2, 104-107.

Steise1, I. M. Paraprofessionals--questions from a traditionalist. Professional Psychology, 1972, $3,331-334$.

Stevenson, E. W., \& Viney, L. L. The effectiveness of nonprofessional therapists with chronic, psychotic patients: An experimental study. The Journal of Nervous and Mental Disease, 1973, 156, 38-46.

Stollak, G. E. The experimental effects of training college students as play therapists. In B. G. Guerney, Jr. (Ed.), Psychotherapeutic agents: New roles for nonprofessionals, parents, and teachers. New York: Holt, Rinehart \& Winston, 1969.

Strupp, H. H., Fox, R. E., \& Lessler, K. Patients view their psychotherapy. Baltimore, Maryland: Johns Hopkins Press, 1969.

Taylor, J. A., \& Spence, K. W. The relationship of anxiety level to performance in serial learning. Journal of Abnormal and Social Psychology, 1952, 44, 61-64.

Truax, C. B. An approach toward training for the aide-therapist: Research and implications. Fayetteville, Ar.: Arkansas Rehabilitation Research and Training Center, 1965.

Truax, C. B. The use of supportive personnel in rehabilitation counseling: Process and outcome. Discussion Papers No. 259. Fayettevilie, Ar.: Arkansas Rehabilitation Research and Training Center, 1967.

Truax, C. B., \& Lister, J. L. Effectiveness of counselors and counselor aides. Journal of Counseling Psychology, 1970, 17, 331-334.

Truax, C. B., \& Wargo, D. G. Psychotherapeutic encounters that change behavior for better or for worse. American Journal of Psychotherapy, 1966, 20, 499-520. 
Umbarger, C. C., Dalsimer, J. S., Morrison, A. P., \& Breggin, P. R. College students in a mental hospital. New York: Grune \& Stratton, 1962.

Wasserman, C. W., McCarthy, B. W., Ferree, E. H. Student paraprofessionals as behavior change agents. Professional Psychology, $1975, \underline{6}, 217-223$.

Wasserman, C. W., Messersmith, C. E., \& Ferree, E. H. Professional therapists, paraprofessional helpers, and graduate students:

An uneasy alliance. Professional Psychology, 1975, $6,337-343$.

Weinberger, G. Comment. Professional Psychology, 1972, $\underline{3}, 335-337$.

Wine, J. Test anxiety and direction of attention. Psychological Bulletin, 1971, 76, 92-104.

Wisocki, P. A. A covert reinforcement program for the treatment of test anxiety. Unpublished doctoral dissertation, Boston Col1ege, 1970 .

Wolff, T. Undergraduates as campus mental health workers. Personnel and Guidance Journal, 1969, 48, 294-304.

Wolpe, J. The practice of behavior therapy. New York: Pergamon Press, 1969.

Zax, M., \& Cowen, E. L. Abnormal psychology: Changing conceptions. New York: Holt, Rinehart \& Winston, 1972.

Zunker, V. G., \& Brown, W. F. Comparative effectiveness of student and professional counselors. Personnel and Guidance Journal, $1966,44,738-743$. 


\section{APPENDIX A}

STAI-S Test Anxiety Questionnaire 
SELF-EVALUATION QUESTIONNAIRE

Developed by C. D. Spielberger, R. L. Gorsuch and R. Lushene STAI FORM $X-1$

NAME

DIRECTIONS: A number of statements which people have used to describe themselves are given below. Read each statement and then blacken in the appropriate circle to the right of the statement. There are no right or wrong answers. Do not spend too much time on any one statement. Answer the statements as to how you would feel taking a test. DATE

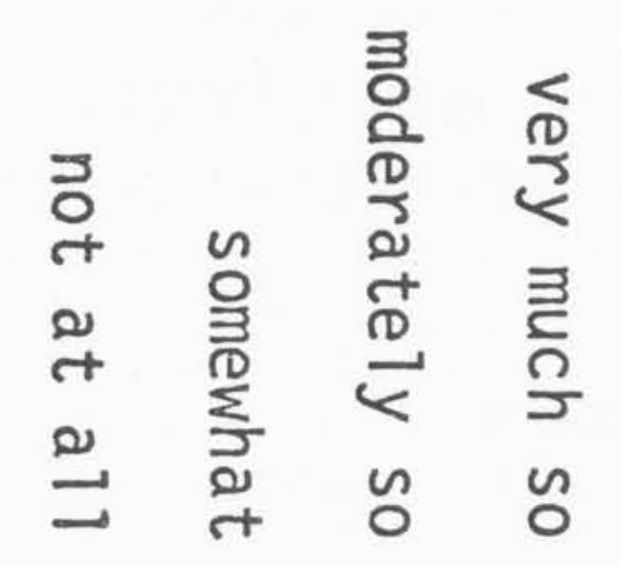

1. I feel calm........................... (2) (4)

2. I feel secure....................... (2) (3) (4)

3. I am tense...................................... (3) (4)

4. I am regretful ..................... (2) (3) (4)

5. I feel at ease ....................... (2) (3)

6. I feel upset ...................... (2) (3) (4)

7. I am presently worrying over possible misfortunes

(1) (2) (3) (4)

8. I feel rested.

(1) (2) (3) (4)

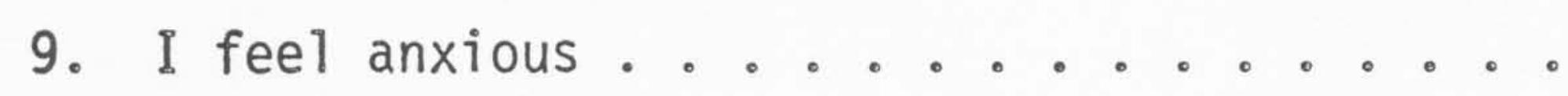

(1) (2) (3) (4)

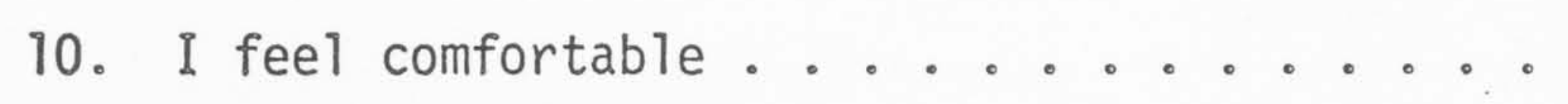

(1) (2) (3) (4)

11. I feel self-confident..........

(1) (2) (3) (4)

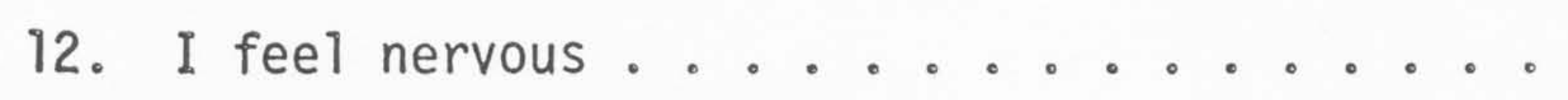

(1) (2) (3) (4)

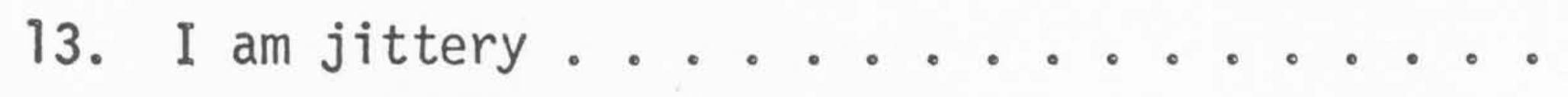

(1) (2) (3) (4)

14. I feel "high strung" ..........

(1) (2) (3) (4)

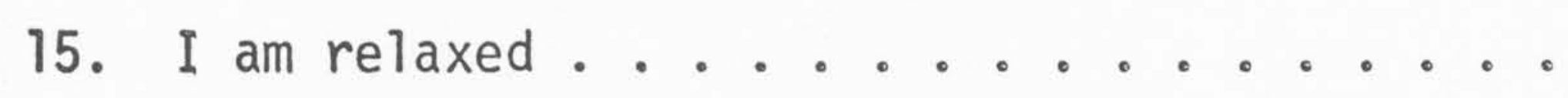

(1) (2)

16. I feel content ............

(1) (2) (3) (4)

17. I am worried ........................ (2)

18. I feel over-excited and "rattled" .....

(1) (2)

(3) (4)

19. I feel joyful.............

20. I feel pleasant.

(1) (2) 
APPENDIX B

AAT Survey 


\section{AAT SURVEY}

Name

This questionnaire deals with your experience and feelings about examinations. Read each item carefully and circle the number which applies to your personal experience. The five different answers for each item are: ALMOST NEVER, RARELY, SOMETIMES, OFTEN, ALMOST ALWAYS. Mark only one of the answers for each item, and be frank and as accurate as you can in choosing the answer that applies to you.

\begin{tabular}{lrr}
$\begin{array}{c}\text { Almost } \\
\text { Never Rarely }\end{array}$ Some- & $\begin{array}{r}\text { Almost } \\
\text { times }\end{array}$ Often \\
\hline
\end{tabular}

1. Nervousness while taking an exam or test hinders me from doing well.

2

3

4

2. I work most effectively under pressure, as when the task is very important.

12

3

4

5

3. In a course where I have been doing poorly, fear of a bad mark cuts down my efficiency.

4. When I am poorly prepared for an exam, I get upset and do even more poorly than I should.

3

4

5. The more important the exam, the more poorly I seem to do.

1

2

3

4

5

6. I may be nervous before starting an exam, but once I start I forget to be nervous.

2

3

4

5

7. I block on exam questions to which I know the answers, even though I might remember them as soon as the exam is over.

8. Nervousness while taking an exam helps me do better.

9. When I start an exam, nothing can distract me.

10. My mind goes blank at the beginning of an exam, and it takes a few minutes before I can function.1 


\begin{tabular}{|c|c|c|c|}
\hline $\begin{array}{l}\text { Almos } \\
\text { Neve }\end{array}$ & Rar & $\begin{array}{l}\text { Some- } \\
\text { times }\end{array}$ & Often \\
\hline
\end{tabular}

11. I look forward to exams.

1

2

3

4

5

12. In courses in which the total grade is based mainly on one exam, I seem to do better than other people.

1

2

3

4

5

13. By the time I start an exam, I am so tired from worrying that I hardly care how well I do.

3

4

5

14. Time pressure on an exam makes me do worse than the rest of the group under similar conditions.

$\begin{array}{lllll}1 & 2 & 3 & 4 & 5\end{array}$

15. If the need arises, I can "cram" just before an exam and remember the material for the exam.

1

2

3

4

5

16. I enjoy taking a difficult exam more than an easy one.

17. I find myself reading exam questions without understanding them, and must go back over them so that they will make sense.

18. The more important the exam, the better I seem to do.

2

3

45

19. When I do poorly on a difficult question at the beginning of an exam, it upsets me so that I block on easy questions later on.

$\begin{array}{llll}2 & 3 & 4 & 5\end{array}$


APPENDIX C

Subject Test Anxiety Scores 
SUBJECT TEST ANXIETY SCORES

\begin{tabular}{|c|c|c|c|c|c|c|c|}
\hline \multirow{3}{*}{$\begin{array}{l}\text { Therapist } \\
\text { Group }\end{array}$} & \multirow{3}{*}{$\begin{array}{l}\text { Subject } \\
\text { Number }\end{array}$} & \multicolumn{6}{|c|}{ Test Anxiety Measures } \\
\hline & & \multicolumn{2}{|c|}{ STAI-S } & \multicolumn{2}{|c|}{ DAAT } & \multicolumn{2}{|c|}{ FAAT } \\
\hline & & Pre & Post & Pre & Post & Pre & Post \\
\hline \multirow[t]{19}{*}{ Professional } & 01 & 62 & 41 & 39 & 22 & 22 & 28 \\
\hline & 02 & 57 & 40 & 24 & 24 & 28 & 28 \\
\hline & 03 & 35 & 34 & 33 & 29 & 19 & 15 \\
\hline & 04 & 48 & 75 & 44 & 39 & 14 & 17 \\
\hline & 05 & 41 & 43 & 35 & 26 & 29 & 34 \\
\hline & 06 & 39 & 34 & 33 & 25 & 24 & 30 \\
\hline & 07 & 62 & 41 & 37 & 27 & 16 & 23 \\
\hline & 08 & 62 & 51 & 30 & 33 & 26 & 25 \\
\hline & 09 & 65 & 58 & 30 & 33 & 27 & 22 \\
\hline & 10 & 59 & 50 & 29 & 25 & 21 & 22 \\
\hline & 11 & 76 & 61 & 40 & 29 & 15 & 23 \\
\hline & 12 & 65 & 56 & 43 & 41 & 15 & 12 \\
\hline & 13 & 57 & 44 & 34 & 30 & 22 & 23 \\
\hline & 14 & 57 & 47 & 26 & 28 & 22 & 25 \\
\hline & 15 & 42 & 40 & 24 & 20 & 23 & 23 \\
\hline & 16 & 68 & 32 & 33 & 33 & 22 & 20 \\
\hline & 17 & 34 & 35 & 26 & 16 & 27 & 16 \\
\hline & 18 & 60 & 41 & 33 & 24 & 17 & 20 \\
\hline & 19 & 67 & 66 & 40 & 36 & 12 & 14 \\
\hline \multirow[t]{7}{*}{ Paraprofessional } & 20 & 49 & 38 & 26 & 24 & 23 & 23 \\
\hline & 21 & 72 & 59 & 40 & 32 & 16 & 21 \\
\hline & 22 & 25 & 52 & 33 & 30 & 21 & 22 \\
\hline & 23 & 62 & 49 & 36 & 32 & 14 & 16 \\
\hline & 24 & 70 & 53 & 32 & 27 & 20 & 18 \\
\hline & 25 & 53 & 57 & 37 & 36 & 15 & 15 \\
\hline & 26 & 60 & 58 & 42 & 35 & 16 & 22 \\
\hline
\end{tabular}

